\title{
Diretrizes do atendimento ao paciente com traumatismo cranioencefálico
}

\author{
Almir Ferreira de Andrade*, Orildo Ciquini Jr.**, Eberval Gadelha Figueiredo***, Roger \\ Schmidt Brock ${ }^{\star * *}$, Raul Marino Jr. ${ }^{* * * *}$ \\ Departamento de Trauma da Sociedade Brasileira de Neurocirurgia \\ Divisão de Clínica Neurocirúrgica e Equipe Médica de Emergência do Pronto-Socorro do Hospital das Clínicas da Faculdade de \\ Medicina da Universidade de São Paulo
}

\section{RESUMO}

A Sociedade Brasileira de Neurocirurgia, pelo Departamento de Trauma, com a Divisão de Clínica Neurocirúrgica da Faculdade de Medicina da Universidade de São Paulo e da Equipe Médica de Emergência do Pronto-Socorro de Neurocirurgia do Hospital das Clínicas da Faculdade de Medicina da Universidade de São Paulo, elaborou as Diretrizes do Atendimento ao Paciente com Traumatismo Cranioencefálico, buscando a homogeneidade de condutas e a redução dos índices de mortalidade e morbidade em todo país. Essas diretrizes possuem uma versão dedicada ao Atendimento Pré-hospitalar (Unidades de Resgate) e ao Atendimento Hospitalar imediato na Sala de Emergência. Com essa uniformização proposta, os estudos epidemiológicos poderão ser realizados de forma mais ampla e com dados mais seguros, permitindo identificar os pontos fracos e atuar com objetivos específicos, visando diminuir a morbidade e a mortalidade do paciente com traumatismo cranioencefálico.

\section{PALAVRAS-CHAVE}

Traumatismo cranioencefálico.

\section{ABSTRACT}

Guidelines for prehospital and Emergency Department management of traumatic head injuries

It is presented the guidelines proposed for management of traumatic and penetrating head injuries in Brazil. It was elaborated by the Department of Trauma of the Brazilian Society of Neurosurgery in association with the Neurosurgical Department of São Paulo University Medical School.

\section{KEYWORDS \\ Brain injury.}

\section{Introdução}

De acordo com estudo epidemiológico realizado recentemente nos Estados Unidos da América, a incidência de casos com traumatismo cranioencefálico (TCE) é estimada em 500 mil pacientes, por ano, em uma população de 250 milhões de habitantes. Dentro dessa casuística,

* Diretor Técnico de Saúde da Equipe Médica de Emergência de Neurocirurgia do HCFMUSP. Presidente do Departamento de Trauma da Sociedade Brasileira de Neurocirurgia. Presidente da Liga de Neurotraumatologia do Mercosul.

** Médico Supervisor da Equipe Médica de Emergência do HCFMUSP.

*** Médico Perceptor da Residência Médica da Divisão de Clínica Neurocirúrgica do HCFMUSP.

**** Diretor da Liga de Neurocirurgia do HCFMUSP.

***** Professor Titular da Divisão de Clínica Neurocirúrgica da FMUSP. 
a taxa de mortalidade verificada como conseqüência direta do TCE (em acidentes de tráfego) atingiu o índice de $10 \%$ (50 mil casos). O mesmo índice (10\%) foi registrado como taxa de morbidade, incluindo-se nesses dados desde a incapacitação leve à dependência total do paciente.

Ressaltamos algumas das conclusões mais importantes desse estudo, referentes à profilaxia do TCE:

1) Os acidentes automobilísticos constituem a principal causa de TCE, alcançando quase $50 \%$ dos casos. A associação de bebidas alcoólicas com esses acidentes chega a $72 \%$, ressaltando-se que essa combinação acarreta não apenas o aumento do risco de acidentes, mas também prejudica a avaliação neurológica do paciente quando alcoolizado.

2) O excesso de velocidade, acima do máximo permitido pela legislação de trânsito, muitas vezes ocasionado pela ingestão de bebidas alcoólicas e drogas, também contribui para o aumento de acidentes.

3) A hipoxia hipóxica é comum em pacientes com TCE, ocorrendo em algum grau em mais de $50 \%$ dos pacientes que respiram espontaneamente à admissão hospitalar.

4) A hipoxia hipóxica cerebral ocorrida desde o momento do acidente até o atendimento, chega a determinar o índice de $30 \%$ de mortalidade, mesmo com um bom atendimento hospitalar especializado.

5) O choque hipovolêmico determina o índice de $28 \%$ de mortalidade.

6) $\mathrm{O}$ atendimento na cena do acidente, segundo a Organização Mundial da Saúde, reduz o índice de mortalidade em $20 \%$ nos acidentes automobilísticos.

7) O uso do cinto de segurança reduz de $40 \%$ a $60 \%$ a ocorrência tanto do TCE grave quanto da mortalidade.

8) Nos acidentes de motocicleta, 53\% das mortes são decorrentes de TCE. O uso de capacete reduz essa mortalidade em $30 \%$.

9) Os novos métodos de proteção, como air bag, diminuem o índice de lesões faciais, assim como promovem uma importante redução na mortalidade por TCE.

Em estudo epidemiológico realizado em 1993, no Estado de São Paulo, considerando-se a população brasileira (150 milhões de habitantes), apurou-se que a mortalidade atingiu $57 \mathrm{mil}$ casos, número que ultrapassa, quase em $50 \%$, a estimativa norteamericana.
A Divisão de Clínica Neurocirúrgica da Faculdade de Medicina da Universidade de São Paulo (FMUSP), por meio de sua Equipe Médica de Emergência do Pronto-Socorro de Neurocirurgia do Hospital das Clínicas, segundo dados estatísticos fornecidos pela Prodesp (Processamento de dados do Estado de São Paulo), no período de oito meses (janeiro a agosto de 1998), atendeu 3.718 pacientes com uma média de 465 pacientes por mês. Cerca de $25 \%$ dos pacientes atendidos foram internados, $77 \%$ dos quais tratava-se de emergência traumática (Quadro 1).

\section{Quadro 1}

Pacientes atendidos pela Equipe de Neurologia de Emergência do Pronto-Socorro do Hospital das Clínicas da Faculdade de Medicina da Universidade de São Paulo, no período de janeiro a agosto de 1998

- Período: janeiro a agosto de 1998

- Atendimentos: 3.718 pacientes (média $=465 / \mathrm{mês}$ )

- Dispensados ou em observação: 2.770 pacientes $(74,5 \%)$

- Internações: 948 pacientes (média $=119 / \mathrm{mês}, 4 / \mathrm{dia})$

Emergências traumáticas: 604 pacientes

Emergências traumáticas com lesões associadas: 131 pacientes

Emergências não-traumáticas: 213 pacientes

- Neurocirurgia por TCE: 133 cirurgias (média $=17 /$ mês)

- Neurocirurgia TCE com lesões associadas: 31 cirurgias (média = 3,8/mês) - Neurocirurgias emergências não-traumáticas: 117 cirurgias (média = 14,6/mês)

- Total de cirurgias: 281 (média $=35,1 /$ mês)

- Total de óbitos: 143 pacientes (média $=17,8$ pacientes $/$ mês ou $15 \%$ do total de pacientes)

Aliando-se aos esforços até agora realizados, a Sociedade Brasileira de Neurocirurgia, por meio do Departamento de Trauma, com a Divisão de Clínica Neurocirúrgica da Faculdade de Medicina da Universidade de São Paulo e da Equipe Médica de Emergência do Pronto-Socorro de Neurocirurgia do Hospital das Clínicas da Faculade de Medicina da Universidade de São Paulo, elaborou as Diretrizes do Atendimento ao Paciente com Traumatismo Cranioencefálico, buscando a homogeneidade de condutas e a redução dos índices de mortalidade e morbidade em todo país. Não desejamos ser absolutamente dogmáticos com a apresentação dessas diretrizes, entretanto, achamos necessário uniformizar as condutas, baseados em literatura consagrada, a fim de unir os neurocirurgiões de urgência em torno de uma postura comum. Essas diretrizes possuem uma versão dedicada ao Atendimento Pré-hospitalar (Unidades de Resgate) e ao Atendimento Hospitalar imediato na sala de emergência. Além disso, apresentam-se as Orientações ao paciente e aos familiares, entregues em folha impressa após alta. Os objetivos maiores são recomendações técnicas de como proceder após um TCE, com ou sem 
alterações hemodinâmicas associadas, concomitantemente aos procedimentos do ATLS (Advanced Trauma Life Suport). Com essa uniformização proposta, os estudos epidemiológicos poderão ser realizados de forma mais ampla e com dados mais seguros, permitindo identificar os pontos fracos e atuar com objetivos específicos, visando diminuir a morbidade e a mortalidade do paciente com TCE.

\section{Descrição}

As Diretrizes do Atendimento ao Paciente com Traumatismo Cranioencefálico compõem-se de 36 páginas. Nas duas páginas iniciais, estão as Diretrizes do Atendimento Pré-hospitalar, o qual deve ser realizado no local do acidente e durante o transporte até a unidade de emergência capacitada mais próxima, sendo direcionadas para as Equipes de Resgate (Corpo de Bombeiros, Polícia Militar, Médicos e Enfermagem). A primeira página é destinada à identificação do paciente e à descrição do mecanismo do trauma, assim como à avaliação inicial pela Escala de Coma de Glasgow (ECGla) e pelo Escore de Trauma Revisado (RTS). Na segunda página, estão descritas as instruções básicas para o atendimento pré-hospitalar segundo orientações do Advanced Trauma Life Suport (ATLS), bem como dados necessários para exame neurológico sumário, com avaliação do nível de consciência, das pupilas, de déficits motores e critérios de gravidade neurológica para a transferência ao hospital especializado.

Nas páginas seguintes, encontram-se as Diretrizes do Atendimento Hospitalar que se iniciam com a identificação do paciente, dos dados epidemiológicos do traumatismo desde o primeiro atendimento até a sala de emergência, da anamnese, do mecanismo do trauma, dos antecedentes individuais, do exame físico geral, da avaliação do nível de consciência pela Escala de Coma de Glasgow à admissão e da gravidade do traumatismo pelo uso do Escore de Trauma Revisado, incluindo as suas variações para crianças (pág. 143). O Escore de Trauma Revisado é uma classificação numérica para se estimar a gravidade do traumatismo, e calculado pelo escore da Escala de Correlação da Escala de Coma de Glasgow (obtido, atribuindo-se novos valores a grupamentos de escores da ECGla) somado à pontuação atribuída aos parâmetros das funções cardiopulmonares (freqüência respiratória e pressão arterial sistólica). A cada parâmetro é dado um determinado valor (quanto menor o valor, pior a função). A gravidade da lesão é estimada pela soma dos números da Escala de Correlação da ECGla e dos parâmetros cardiopulmonares, sendo o menor valor igual a zero e o maior 12 (pág. 144).

Na página seguinte, estão listadas as Condutas Básicas no Atendimento Hospitalar ao paciente com traumatismo, segundo as normas do ATLS, no que diz respeito ao atendimento primário, manobras de reanimação e avaliação secundária do paciente hemodinamicamente estável.

A seguir, os Sinais Neurológicos de Localização das lesões (padrão pupilar, padrões e anormalidades respiratórias, reflexos do tronco cerebral, posturas patológicas de decorticação e decerebração, déficits motores ou sensitivos) podem ser rapidamente descritos e avaliados, preenchendo-se a página correspondente, devendo-se prestar atenção às lesões associadas, como lesão da membrana timpânica e da coluna cervical, que estão associadas em $20 \%$ dos pacientes em coma, impedindo, respectivamente, a realização dos reflexos vestibulocular e oculocefálico.

$\mathrm{Na}$ página seguinte, anotam-se os resultados dos Exames de Imagem. No craniograma simples, a presença de fratura indica a necessidade da realização de tomografia computadorizada (TC). Se a fratura cruzar o trajeto de estruturas vasculares, por exemplo, a artéria meníngea média, a pirâmide petrosa ou os seios venosos, há maior risco de lesão dessas estruturas provocando o desenvolvimento de hematomas. A lesão de nervos cranianos também pode ser correlacionada da mesma maneira. Fraturas nas paredes dos seios da face podem sugerir a localização de fístulas liquóricas. A TC pode apresentar-se normal, a despeito do TCE ser grave (ECGla abaixo de 9), como verificado quando há anoxia, lesão axonal difusa, embolia gordurosa, comoção cerebral, lesão vascular traumática e hemorragia meníngea traumática grau zero; nessas situações, os índices de pressão intracraniana estão elevados em $13 \%$ dos casos. Pacientes com TC normal que apresentarem pelo menos dois dos seguintes fatores: a) idade $>40$ anos; b) pressão arterial média $<90 \mathrm{mmHg}$; c) postura motora de decorticação ou decerebração, terão pressão intracraniana (PIC) elevada em cerca de $60 \%$ das vezes. Quando há suspeita de lesão vascular traumática, por exemplo, quando se evidencia hemiplegia completa em paciente consciente, é necessária a realização de exames complementares como o doppler transcraniano e angiografia isotópica ou convencional para o diagnóstico etiológico da lesão.

A contusão cerebral focal é anatomopatologicamente definida por quatro fatores: hemorragia, isquemia, edema e necrose que, na tomografia, se revela como lesão focal de aspecto heterogêneo denominada lesão em "sal e pimenta". A área de infarto, que representa o edema anóxico isquêmico, pode apresentar-se sob forma de lesão focal, principalmente na 
região do lobo temporal, após herniação uncal por compressão da artéria cerebral posterior, ou como lesões em outros territórios vasculares como o da artéria cerebral média. A área de edema cerebral, na TC, quase sempre é perilesional (edema vasogênico) e necessita acompanhamento rigoroso, pois pode ocorrer expansão somada à lesão primária. A hemorragia meníngea traumática, que pode ser focal ou difusa, pode evoluir de forma semelhante à hemorragia espontânea, levando ao infarto cerebral por vasoespasmo, e causar óbito. Os afundamentos cranianos, de modo geral, têm indicação de craniotomia com osteossíntese, que deve ser imediata em fraturas expostas. Quando ocorre sobre o trajeto dos seios venosos a indicação cirúrgica é mais restrita. $\mathrm{O}$ pneumocrânio, que é caracterizado pela imagem de ar no espaço subaracnóideo, cisternal, ventricular, subdural ou extradural, indica a presença de fístula liquórica, mesmo sem débito evidente. Pode-se apresentar sob a forma hipertensiva, situação na qual deve ser drenado por trépano-punção. A punção deve ser realizada utilizandose uma seringa de $20 \mathrm{cc}$ sem o êmbolo e cheia de soro fisiológico, conectada a uma agulha, permitindo a saída do ar e sua troca por líquido. Outra opção, nessa situação, é a craniotomia e correção direta da fístula dural. Mais recentemente, temos empregado a oxigenação hiperbárica com bons resultados, clínicos e radiológicos, inclusive com menor incidência de infecção.

$\mathrm{Na}$ avaliação da TC, destacamos a importância da medida do desvio das estruturas da linha média (DLM) produzido por hematomas, tumefação hemisférica ou contusões cerebrais. Esse valor é avaliado em milímetros a partir da linha média do crânio até o septo pelúcido ou até a linha média do terceiro ventrículo desviados. Existe uma correlação direta do DLM com o nível de consciência e prognóstico. Em desvios de $5,4 \mathrm{~mm}$ a $12,2 \mathrm{~mm}$, o paciente geralmente está com diminuição do nível de consciência (confusão mental, obnubilação e torpor). Com DLM de $12,2 \mathrm{~mm}$ a $15 \mathrm{~mm}$, o paciente está em coma e, acima desse valor, além do coma, o prognóstico é grave. A medida do DLM é um importante parâmetro para a indicação de tratamento cirúrgico. Outro dado importante que a TC pode oferecer é a medida do volume dos hematomas e contusões, calculada pela fórmula da elipse (volume $=$ 4/3 x 3,14 x A x B x C, em que A, B e C representam, respectivamente, os maiores valores dos raios ânteroposterior, látero-lateral e craniocaudal). Esses dados podem ser calculados durante a própria realização da TC, por programas de cálculo do próprio aparelho, ou pode ser obtido por medida visual da lesão, utilizandose a escala de correção que aparece impressa no próprio filme. Em relação ao volume dos hematomas e contusões, observa-se, na literatura, que os de volumes de até $29 \mathrm{~cm}^{3}$ são reabsorvidos, os de $30 \mathrm{~cm}^{3}$ a $50 \mathrm{~cm}^{3}$ têm indicação cirúrgica, e aqueles acima de $50 \mathrm{~cm}^{3}$ produzem mortalidade de $90 \%$, com ou sem intervenção cirúrgica. Quando os hematomas se localizam no compartimento infratentorial, observa-se que hematomas menores que $16 \mathrm{~cm}^{3}$, não têm indicação cirúrgica, pois são reabsorvidos. Quando apresentam volume superior a $16 \mathrm{~cm}^{3}$, são potencialmente de indicação cirúrgica, dependendo do quadro clínico, podendo-se realizar desde a derivação ventricular, quando acompanhado de hidrocefalia, até a drenagem do hematoma. Quando o volume do hematoma na fossa posterior é superior a $23 \mathrm{~cm}^{3}$, a conduta deve ser cirúrgica, independentemente do quadro clínico.

As lesões cerebrais difusas (tumefação cerebral e lesão axonal) também são identificadas em espaço próprio. Na tumefação cerebral difusa, é importante identificar quais cisternas apresentam-se diminuídas à tomografia, uma vez que $55 \%$ dos pacientes com as cisternas quadrigeminal e perimesencefálica comprimidas apresentam PIC mantida acima de $30 \mathrm{mmHg}$, o mesmo ocorrendo em $75 \%$ daqueles com cisternas ausentes. O III ventrículo colabado é, também, indicativo de aumento da pressão intracraniana. A tumefação cerebral hemisférica está associada com o hematoma subdural agudo em $85 \%$ dos casos, com o hematoma extradural em $9,6 \%$ e com a ausência de hematomas em 5,4\%; nesses casos, a avaliação do DLM segue as mesmas regras dos hematomas e contusões.

Os pacientes com lesões cerebrais difusas podem ser classificados segundo os achados tomográficos, baseado na evidência de compressão das cisternas e desvios de linha média. Na lesão difusa do tipo I, não há alteração visível à TC; aqueles classificados como portadores de lesão difusa do tipo II apresentam cisternas evidentes à TC e DLM inferior a $5 \mathrm{~mm}$, podendo estar incluídos fragmentos ósseos e corpos estranhos; os pacientes com lesões classificadas como sendo do tipo III (tumefação cerebral difusa) apresentam cisternas comprimidas ou ausentes, não apresentando, entretanto, DLM superior a $5 \mathrm{~mm}$, como se evidencia nas lesões classificadas no tipo IV, as quais apresentam DLM superior a $5 \mathrm{~mm}$. É importante lembrar que em todos esses grupos não se evidenciam lesões hiperdensas ou de densidade de volume maior que $25 \mathrm{ml}$, que caracterizariam efeito expansivo. Esses podem, ou não, necessitar de tratamento cirúrgico.

Na página 148 encontram-se listados os Critérios para Admissão ou Observação dos pacientes que, ao exame físico inicial, encontram-se conscientes e orientados $(\mathrm{ECGla}=15)$. Esses critérios são baseados no exame físico geral (sinais e sintomas de fratura de base de crânio), do exame neurológico (sinais focais de localização ou alterações cognitivas) e de critérios radiológicos (lesão intracraniana à TC). Dessa maneira, 
é difícil se estabelecer dados epidemiológicos confiáveis, visto que a grande maioria desses pacientes não chegam a procurar o hospital. Os pacientes atendidos que não apresentarem critérios para admissão imediata (TCE leve com baixo risco para lesão intracraniana), ou após 12 horas de observação (TCE leve com alto risco para lesão intracraniana), constituem $74,5 \%$ dos pacientes que procuram serviços de saúde e serão liberados com alta do consultório hospitalar ou da sala de emergência. Os demais $(25,5 \%)$ com TCE leve e alto risco para lesão intracraniana serão admitidos. Aos que não apresentaram os critérios para admissão imediata ou após 12 horas de observação, recebem, eles próprios ou seus familiares, as Orientações aos Familiares de Paciente com TCE (pág. 149). Essas orientações preconizam manter o paciente em companhia de alguém confiável, especialmente durante as 24 horas iniciais, consideradas mais críticas. Nesse período, devem ser observados os 15 sinais e sintomas listados, e há a orientação para que, na ocorrência de algum desses sinais ou sintomas, o paciente retorne imediatamente ao hospital.

O Doppler Transcraniano (DTC) (pág. 150) constitui uma metodologia de importância fundamental na abordagem e no acompanhamento de pacientes com traumatismos cranioencefálicos, possibilitando o diagnóstico precoce das várias condições póstraumáticas com repercussão hemodinâmica encefálica, como tumefação cerebral hiperêmica ou oliguêmica, vasoespasmo pós-traumático do sistema carotídeo ou vertebrobasilar, hipofluxo cerebral (choque hipovolêmico), trombose arterial intra ou extracraniana, hipertensão intracraniana e isquemia cerebral. No TCE, a principal condição associada com o aumento de velocidade de fluxo em todo o sistema carotídeo ou vertebrobasilar é a tumefação cerebral hiperêmica, difusa ou focal, e tumefação cerebral oliguêmica em que há distúrbio da auto-regulação microcirculatória que pode ser global ou circunscrita a um território arterial. Assim, o aumento de velocidade de fluxo é acompanhado de índice de resistência arteriolar rebaixado, representado pelo índice de pulsatilidade (IP). A redução do valor do IP pode ocorrer precocemente após a TCE, antes mesmo do aparecimento tomográfico da tumefação cerebral.

O vasoespasmo encefálico é uma importante causa de piora neurológica, ou manutenção do estado de rebaixamento do nível de consciência, e infartos encefálicos em doentes com hemorragia subaracnóide traumática, aumentando a morbidade e a mortalidade desses pacientes. O exame de doppler transcraniano é útil ao demonstrar precocemente e monitorar o curso do vasoespasmo permitindo o tratamento mais adequado. O mecanismo de detecção do vasoespasmo baseia-se no aumento de velocidade de fluxo em situações de estreitamento da luz arterial. Porém, outras situações podem resultar em aumento de velocidade do fluxo sangüíneo em artérias intracranianas sem, no entanto, significar vasoespasmo, como verificado na tumefação cerebral hiperêmica, febre e anemia. Seria, portanto, necessário diferenciar o vasoespasmo cerebral dessas outras condições. Isso é possível comparando-se as velocidades de fluxo nas artérias intracranianas com as extracranianas. No vasoespasmo, há aumento de velocidade apenas na área turbulenta intracraniana estenótica, o que não acontece em outras condições. Estabeleceu-se, então, o índice de Lindegaard (IL) que compara a velocidade do fluxo na artéria cerebral média com a da artéria carótida interna extracraniana homolateral: $\mathrm{IL}=\mathrm{VmACM} /$ VmACI. O valor IL $>3$ indica vasoespasmo e IL $>6$ indica vasoespasmo grave.

O doppler é, no momento, o único exame que se dispõe para detectar êmbolos na circulação cerebral, em tempo real. A passagem de material embólico produz som e sinal característicos no espectro. $\mathrm{O}$ achado de êmbolos na circulação encefálica em doentes politraumatizados sugere a dissecção da artéria carótida interna extra ou intracraniana, das artérias vertebrais ou basilares. É possível a avaliação da eficiência do tratamento, ao monitorizar o número de êmbolos antes e após a anticoagulação. A Equipe Médica de Emergência da Divisão de Clínica Neurocirúrgica do Hospital das Clínicas da FMUSP introduziu o exame de doppler transcraniano como metodologia de rotina na avaliação da hemodinâmica cerebral dos pacientes na admissão e principalmente na UTI.

O doppler transcraniano pode ser utilizado também para a confirmação do diagnóstico de morte encefálica, ao demonstrar ausência da hemodinâmica de fluxo sangüíneo progressivo (ausência de perfusão encefálica).

A Monitorização da Pressão Intracraniana (pág. 151) é de importância na abordagem diagnóstica e terapêutica de pacientes com TCE, sendo atualmente procedimento de rotina em vários centros neurocirúrgicos. A elevação da PIC pode causar isquemia por redução do fluxo sangüíneo encefálico, hérnias cerebrais, compressão e torção vascular que pioram o prognóstico. Utilizando-se também do valor do índice de pulsatilidade, que denota resistência vascular em artérias isoladas do polígono de Willis, pode-se indiretamente inferir sobre alterações da PIC. Um aumento da PIC provocará aumento diretamente proporcional do IP e, portanto, a avaliação com exames seriados, pode fornecer parâmetros para acompanhamento da evolução da PIC. Dessa maneira, o exame seqüencial ou a monitoração contínua poderá 
indicar piora ou melhora do doente quanto a esse aspecto. Acredita-se que, no futuro próximo, se consiga estimar a PIC de uma maneira confiável e não-invasiva pela análise de parâmetros hemodinâmicos intracranianos obtidos pelo doppler transcraniano e pelas curvas de pressão arterial sistêmica, entre outros parâmetros fisiológicos. Entretanto, o doppler não medirá os níveis de PIC e sua análise qualitativa (ondas intracranianas patológicas "A" e " $B$ " e determinação da complacência cerebral).

As análises qualitativa e quantitativa dos dados fornecidos pela monitorização da PIC são necessárias para a avaliação dos pacientes, principalmente aqueles cujo quadro neurológico não se pode monitorizar clinicamente (pacientes em coma). Atualmente, são mais utilizados os monitores de fibra óptica (Camino R/M 1000 Ladd ${ }^{\mathrm{R}}$ ), Strain Gauge intracraniano com cabo de cobre (Codman ${ }^{\mathrm{R}}$ ) e o Strain Gauge extracraniano com cabo hidrostático, todos com suas vantagens e desvantagens. As indicações para a monitorização da PIC, critérios de inclusão e exclusão, bem como as normas para o tratamento da hipertensão intracraniana seguem-se nas páginas 151 e 168. Atualmente, usamos de rotina, concomitantemente à monitorização da PIC, a determinação da temperatura intracraniana e sua correlação com a temperatura axilar e retal, o que nos orienta a terapêutica específica da hipertermia e o controle da hipotermia cerebral espontânea ou induzida.

Nas páginas seguintes, são listadas as diferentes condutas a serem adotadas de acordo com o nível de consciência determinado pela ECGla e os achados de exames dos pacientes admitidos. Cada algoritmo apresenta, no alto da folha, em uma linha, os critérios tomográficos de inclusão no grupo, seja pela medida do DLM, seja pela medida do volume do hematoma ou da contusão. No primeiro algoritmo (pág. 152), são listadas as condutas a serem tomadas em pacientes com TCE, conscientes, orientados, sem sinais ou sintomas neurológicos e/ou neuropsicológicos, mas que apresentam lesão à TC, com DLM menor que $5 \mathrm{~mm}$ e hematomas sem indicação cirúrgica (volume menor que $30 \mathrm{cc}$ no compartimento supratentorial ou menor que $16 \mathrm{cc}$ no infratentorial), constituindo o terceiro grupo de pacientes com ECGla=15. Chamamos a atenção para o fato de que os hematomas extradurais da fossa média ou posterior, com ou sem lesões associadas, têm potencialmente indicação de tratamento cirúrgico, independentemente desse quadro clínico, visto a possibilidade de rápida piora do quadro neurológico (talk and deteriorate). A opção pelo tratamento clínico desses pacientes, implica na internação por vários dias, sob observação clínica e controle tomográfico seqüencial, principalmente entre o $7^{\circ}$ e o $15^{\circ}$ dia, quando se dá a segunda expansão dos hematomas extradurais pequenos, o que pode levar à morte súbita e inesperada desses pacientes (talk and die).

O segundo algoritmo (pág. 153) refere-se ao quarto grupo de pacientes com TCE, conscientes e orientados $(E C G l a=15)$ com sinais e sintomas neurológicos e/ou neuropsicológicos, e que à TC apresentam DLM menor que $5 \mathrm{~mm}$ e hematomas sem indicação para tratamento cirúrgico. Os hematomas extradurais, estando ou não associados com outras lesões com sinais e sintomas neurológicos, têm indicação de tratamento cirúrgico, principalmente quando situados na fossa média ou posterior. Na página 154, encontra-se listado o quinto grupo de pacientes que, apesar de conscientes $($ ECGla $=15)$, devem ser admitidos para conduta terapêutica adequada. São pacientes que apresentamse conscientes à admissão e têm características clínicas, radiológicas ou neuropsicológicas particulares, incluindo-se aqueles com traumatismo raquimedular, com ou sem lesão intracraniana associada.

Apresentam-se também os critérios para admissão e manuseio imediato do sexto grupo, constituído de pacientes com TCE que, à admissão, apresentam 15 pontos na ECGla, com sinais e sintomas neurológicos e que evoluem com piora na pontuação da ECGla (talk and deteriorate and/or die). Esses pacientes apresentam o assim denominado intervalo lúcido, observado nas lesões focais e na tumefação cerebral, e não apenas nos hematomas extradurais como consagrado anteriormente pela literatura neurotraumatológica. Esses pacientes, após atendimento inicial na sala de emergência, são admitidos na Unidade de Terapia Intensiva ou Semi-intensiva e submetidos aos exames complementares necessários.

O sétimo grupo (pág. 155) é constituído por pacientes classificados como vítimas de TCE moderada ou grave e aqueles que, na cena do acidente, apresentavam escore 15 na ECGla e que, durante o transporte, na observação ou admissão, evoluíram com quadro clínico de herniação cerebral, caracterizada por coma, midríase uncal, irregularidade respiratória, bradicardia e hipertensão arterial sistêmica (tríade de Cushing).

As diferentes condutas terapêuticas indicadas para pacientes com tumefação cerebral hemisférica (TCH) isolada ou associada com outras lesões intracranianas, passíveis de cirurgia, com DLM maior que 5 mm, são listadas na página 156 .

A seguir (pág. 157) são apresentadas as condutas em pacientes com rebaixamento do nível de consciência (ECGla $<15)$, nos quais a TC mostra 
aumento do volume do parênquima cerebral com diminuição de cisternas e ventrículos, e o DTC sugere hiperemia, oliguemia ou vasoespasmo, podendo, dessa maneira, apresentar tumefação cerebral difusa e/ou lesão axonal difusa (LAD). A LAD é classificada em graus de severidade clínica (leve, moderada ou grave) e segundo os achados tomográficos.

Na página 158, são apresentadas as diretrizes do tratamento de pacientes com TCE grave associado com choque hipovolêmico. Esses pacientes são divididos em cinco grupos, de acordo com a gravidade. Para cada grupo, são apresentadas as condutas defendidas pelas normas do ATLS, assim como as diretrizes propostas por nós (Neuro).

Os afundamentos de crânio ocorrem mais comumente quando um impacto de alta energia ocorre em uma pequena área da calota craniana. Pode ser classificado segundo o grau de desnivelamento entre as respectivas camadas da tábua óssea do crânio, desde um simples desnivelamento a um afundamento completo. São também classificados como aberto ou fechado, dependendo da existência ou não de solução de continuidade de pele. O local, as classificações acima e a presença de lesões associadas determinam a conduta. Destacamos alguns tipos de afundamento de crânio correlacionando-os com as medidas cirúrgicas apropriadas (pág. 159). Quando situados sobre seios venosos durais, a angiografia é necessária. O tratamento depende da localização da lesão, do estado clínico do paciente e da presença de lesões associadas, podendo variar desde o tratamento clínico, passando pela anticoagulação, simples ligadura ou reparo do seio lesado. Nos afundamentos fechados em pacientes neurologicamente estáveis, a conduta inicial não deve ser cirúrgica, a menos que a lesão se torne sintomática. Nos pacientes com ferimentos expostos, com oclusão total ou com seio patente à angiografia, ou naqueles com hematomas intracranianos de indicação cirúrgica inequívoca, a exploração cirúrgica é indicada de imediato. Quando houver estenose parcial de seio venoso em pacientes neurologicamente estáveis, além de debridamento superficial, pode ser realizado tamponamento simples do seio, reparo direto ou com enxerto autólogo ou interposição de enxerto de safena, utilizado, em casos de avulsão da parede do seio, dependendo da extensão da lesão. Esse último procedimento está associado com um alto índice de trombose pós-operatória. De qualquer maneira, o reparo deve ser realizado sempre que possível, apesar de não ser procedimento simples, exceções feitas a casos de lesão linear, e que apresentam problemas técnicos como a quantidade de fluxo sangüíneo envolvido, a ocorrência de embolia aérea e de tumefação cerebral, além da dificuldade em preservar as veias corticais, previamente lesadas.

Em relação à localização da lesão do seio venoso, é clássico o conhecimento de que o terço anterior do seio longitudinal pode ser ligado sem morbidade adicional, as localizadas no terço médio têm alto risco de complicações, caso o seio seja ligado, enquanto aquelas que interessam o terço posterior devem ser reparadas sem nunca ligar o seio.

As diretrizes para os pacientes com ferimentos por projétil de arma de fogo dependem dos achados clínicos e tomográficos (pág. 160). O óbito da vítima ocorre no local da agressão em $70 \%$ das vezes, e a evolução depende diretamente da trajetória do projétil e do quadro clínico à admissão. A conduta varia desde a simples limpeza cirúrgica do orifício de entrada do projétil (quando o paciente apresenta escore na ECGla menor ou igual a cinco e na ausência de hematomas) até craniotomia com limpeza cirúrgica dos primeiros $7 \mathrm{~cm}$ do trajeto do projétil (se transfixante bilateral) ou craniotomia osteoplástica com duroplastia para exérese de hematomas intra e extra-axiais, seguida de monitorização contínua da PIC, após síntese da laceração dural (em pacientes com escore superior a 5 na ECGla, ou em crianças). O projétil localizado no interior de um ventrículo ou cisterna deve ser retirado, pois há o risco de migração ou de lesão vascular. Quando, em tomografias seqüenciais, verifica-se migração tecidual, a indicação cirúrgica se impõe. A realização de estudo angiográfico se faz necessário devido à incidência de lesões vasculares traumáticas, iniciais e tardias.

No ferimento por arma branca, o instrumento utilizado é removido pelo agressor em $76 \%$ das vezes. Quando há retenção desta ou parte dela, deve ser retirada sempre por meio de craniotomia circunferencial ao objeto perfurante (pág. 161). Nesses casos, a evolução depende também diretamente da trajetória atingida pela arma na penetação e do quadro clínico à admissão. Além da tomografia de crânio, deve-se realizar angiografia cerebral para programação da retirada do objeto com segurança, correlacionando-o com a proximidade de vasos e identificando possíveis lesões vasculares. Quando o objeto é retirado pelo agressor ou inadvertidamente pelo médico, o prognóstico piora e a craniotomia deve ser realizada circunferencialmente à lesão penetrante, com limpeza cirúrgica profilática contra infecções e hematomas pósoperatórios. A angiografia cerebral deve ser repetida a partir do $10^{\circ}$ - pós-operatório, pois os aneurismas traumáticos se formam geralmente nesse período e constituem $10 \%$ das complicações.

Os algoritmos com as diretrizes para atendimento de pacientes com fístula liquórica traumática são 
apresentados nas páginas 162 a 164. A incidência de fístula liquórica, após traumatismo craniano nas crianças, é até dez vezes menor que nos adultos. Isso se deve à maior flexibilidade do crânio, à menor incidência de impacto frontal e de TCE, além do fato de os seios paranasais não estarem ainda pneumatizados. A concomitância de lesões vasculares ou de nervos cranianos e a presença ou não de pneumocrânio hipertensivo são decisivos na evolução da conduta. $\mathrm{O}$ tratamento inicial, com observação clínica e antibioticoterapia profilática, pode evoluir para abordagens cirúrgicas complexas, se não houver remissão. A presença de pneumocrânio hipertensivo indica a necessidade do tratamento com oxigenação em câmara hiperbárica ou punção da bolha gasosa quando o quadro clínico assim o indicar.

O espancamento infantil (pág. 165) corresponde a $10 \%$ dos traumas em crianças menores de 5 anos, culminando em $10 \%$ a $27 \%$ de mortalidade e $25 \%$ de danos neurológicos graves. Pode ser classificado de diversas naturezas como a criança espancada, a síndrome de Caffey, "shaken-baby" e criança negligenciada (que consideramos como a mais freqüente). Os aspectos da história e da relação familiar, assim como a reação familiar ao trauma e sinais de exame físico (múltiplas fraturas em tempos diferentes, calos ósseos) devem levantar a suspeita de espancamento infantil. Nesses casos, devem ser acionados o Serviço Social e o Juizado de Menores.

Os traumatismos obstétricos mais freqüentes, seus sinais, sintomas e tratamentos são apresentados na página 166.

Pacientes com alteração neurológica e TC normal, especialmente aqueles com história de múltiplos traumas podem apresentar um dos seguintes diagnósticos: hipoxia, comoção cerebral, LAD, hemorragia meníngea grau 0 (sinais de hemorragia intracraniana não-detectáveis à TC), embolia gordurosa, lesões vasculares traumáticas e fístulas liquóricas, todos necessitando de acompanhamento rigoroso pela equipe médica, com suporte básico em UTI, monitorização contínua da PIC e temperatura cerebral, assim como hipotermia leve quando necessário. O diagnóstico e o método terapêutico específico para cada situação é exposto na página 167.

Na página 168 encontram-se as diretrizes básicas para o tratamento da hipertensão intracraniana (HIC). Este tratamento deve ser iniciado na presença de alguns sinais de hipertensão intracraniana: PIC maior que $15 \mathrm{mmHg}$ na presença de lesão expansiva, principalmente nos lobos temporais, que se torna potencialmente cirúrgica se a PIC ficar acima de $20 \mathrm{mmHg}$ por mais de 5 minutos; se a compressão jugular por 10 segundos traduzir complacência baixa, ou quando o mesmo ocorre com a elevação da cabeça até $30^{\circ}$, identificada pelo não retorno da PIC aos níveis normais; identificação de ondas patológicas (A e B) de pressão intracraniana com grande amplitude (complacência cerebral baixa). Nessas situações, devem ser instituídas medidas clínicas e realizada a TC para a identificação da perda da complacência intracraniana ou de lesão passível de tratamento cirúrgico. Todo o tratamento visa manter a pressão de perfusão cerebral (PPC) constante, definida como a diferença entre a pressão arterial média (PAM) e pressão intracraniana. APPC deve ser mantida entre $80 \mathrm{mmHg}$ e $150 \mathrm{mmHg}$.

A PIC pode ser reduzida, elevando-se o decúbito do paciente a cerca de $30^{\circ}$, o que facilita a drenagem venosa cerebral, diminuindo o volume sangüíneo cerebral (VSC) sem comprometer a perfusão encefálica, evitando a queda da PPC e a ocorrência de lesões isquêmicas, facilitando o manuseio do paciente pela enfermagem para evitar e combater a HIC. A hiperventilação controlada (mantendo a $\mathrm{PCO}_{2}$ entre $30 \mathrm{mmHg}$ e $35 \mathrm{mmHg}$ ) promove a elevação do $\mathrm{pH}$ periarteriolar, causando a vasoconstricção e a redução do VSC. O manitol a 20\% faz parte do arsenal terapêutico, devendo ser administrado na dose de $0,3 \mathrm{~g} / \mathrm{kg} / \mathrm{dose}$ a $1,0 \mathrm{~g} / \mathrm{kg} /$ dose. O manitol, por seu efeito hiperosmótico, provoca transferência de líquido do espaço extra para o intravascular, levando à hemodiluição com diminuição da viscosidade sangüínea, a qual ocasiona um aumento da PPC. A hemodiluição melhora o fluxo sangüíneo encefálico que, por sua vez, permite perfusão tecidual melhor; também eleva o $\mathrm{pH}$ periarteriolar, promovendo vasoconstricção e redução do VSC. Esse efeito ocorre cerca de cinco minutos após a infusão do manitol e a PIC é mantida baixa subseqüentemente, por desidratação do parênquima cerebral, pelo efeito hiperosmótico do manitol.

O uso de sedativos (midazolam) e fentanil visa permitir uma boa dinâmica respiratória, principalmente nos pacientes agitados que não apresentam lesões focais responsáveis por esse quadro clínico. A sedação e a curarização de ação rápida, utilizando brometo de pancurônio, mantêm a musculatura relaxada, facilitando a ventilação. Os barbitúricos podem ser usados também como sedativos ou como agentes para coma induzido, com a finalidade de reduzir a taxa metabólica cerebral e provocar vasoconstrição em pacientes que apresentam swelling hiperêmico, reduzindo o consumo cerebral de oxigênio $\left(\mathrm{CMRO}_{2}\right)$. Apesar de amplamente estudado, não há comprovação clínica do efeito neuroprotetor dos barbitúricos, principalmente com doses não-monitorizadas por meio do eletroencefalograma ou da temperatura cerebral. Entretanto, o uso de barbitúricos, devido à familiaridade e ao seu efeito vasoconstritor cerebral, é muito difundido e é por nós empregado. A literatura atual, entretanto, não preconiza 
o uso do barbitúrico nas situações em que haja lesão nas células do sistema nervoso central, pois permite a disponibilidade de oxigênio para a produção energética mitocondrial nessa situação. É contra-indicado se houver instabilidade hemodinâmica, devido aos efeitos miocardiotóxicos. O uso de doses elevadas de barbitúrico (coma barbitúrico) tem sido abandonada na maior parte dos centros de neurotraumatologia, por não ter eficácia comprovada. Atualmente usamos, no nosso serviço, sedação barbitúrica com monitorização de temperatura cerebral, concomitantemente à monitorização da PIC. Achamos também necessária a monitorização rigorosa por meio do eletroencefalograma (pág. 169).

Apesar de ser de difícil instalação, em situações de traumatismo, devido ao colabamento ventricular, a monitorização intraventricular da PIC é a mais fidedigna, além de permitir a retirada de pequenas quantidades de LCR para análise ou redução da PIC.

A hipotermia induzida leve (entre $34^{\circ} \mathrm{C}$ e $35^{\circ} \mathrm{C}$ ) ou moderada (entre $32^{\circ} \mathrm{C}$ e $33^{\circ} \mathrm{C}$ ) pode ser utilizada como recurso para a diminuição da hipertensão intracraniana e combater a hipertermia, ou como proteção cerebral, com ou sem hipertensão intracraniana nos pacientes graves. O protocolo, contendo as etapas e monitorizações necessárias à instituição da hipotermia, assim como sua metodologia, são apresentados na página 170 .

$\mathrm{Na}$ página 171 , encontra-se o protocolo de diagnóstico e o controle concomitante da PIC e temperatura cerebral. São listadas três condutas e abordagens diferentes, segundo o tipo de acometimento do paciente.

Nas páginas 172 e 173, colocamos as diretrizes básicas da monitorização hemometabólica intermitente e oximetria contínua da saturação de oxigênio do bulbo da veia jugular. A monitorização hemometabólica por método intermitente pode ser realizada por meio da diferença arteriovenosa de saturação de $\mathrm{O}_{2}$, verificada entre amostras de sangue obtidas de um cateter posicionado no bulbo da jugular e amostras de sangue obtidas da artéria radial ou femoral, repetidamente. Consiste em se determinar a taxa de extração cerebral de oxigênio, identificada por meio da medida da saturação de oxigênio no sangue jugular $\left(\mathrm{SvjO}_{2}\right)$, subtraída à saturação de oxigênio do sangue arterial $\left(\mathrm{SaO}_{2}\right)$. É método útil para o diagnóstico de hipoxia oligoêmica, hipoxia hipoxêmica e hiperemia cerebral, e para se instituir as terapias específicas segundo as diretrizes básicas expostas na página 170 . A extração cerebral de oxigênio $\left(\mathrm{ECO}_{2}\right)$ abaixo de $24 \%$ diagnostica hiperemia cerebral e, acima de $42 \%$, hipoxia oligoêmica. Os valores normais variam entre $24 \%$ e $42 \%$.
A oximetria contínua do bulbo da jugular é feita por um cateter de fibra óptica, em pacientes com menos de nove pontos na ECGla. É necessária a calibração do oxímetro a cada 12 horas. O protocolo para o tratamento de pacientes com TCE grave com monitorização contínua da PIC e da saturação arteriovenosa jugular simultânea, até 10 dias após o início do TCE, está apresentado na página 173. Ainda nessa página, apresenta-se o protocolo para o tratamento de pacientes com lesões cerebrais graves por TCE, com base na monitorização da oximetria do bulbo da jugular. A saturação venosa de $\mathrm{O}_{2}$ maior que $90 \%$, determinado pela oximetria contínua do bulbo da jugular é indicativa do diagnóstico de morte cerebral.

Na página 174, apresenta-se a Escala de Evolução de Glasgow, a qual quantifica o grau de incapacidade do paciente que sofreu TCE. Como a maioria dos pacientes com TCE são adultos jovens e com a recente mudança da legislação, é importante que o neurocirurgião tenha conhecimentos clínicos e médicolegais sobre o diagnóstico de morte encefálica, cujos critérios, normas e aspectos legais são expostos nas páginas 174 e 175. Devem-se observar as exigências e determinações do Conselho Federal de Medicina (CFM), o qual afirma que cabe ao médico o diagnóstico definitivo de morte, e que o diagnóstico de morte encefálica no paciente com escore 3 na ECGla, sem reflexos de tronco cerebral, em coma profundo e em apnéia deve ser confirmado após dois exames com intervalo de tempo determinado segundo a idade, por exames subsidiários, como a utilização do eletroencefalograma. O CFM determina os demais métodos de confirmação de morte encefálica, devendo-se atentar para a escolha do melhor método em cada situação.

Tradicionalmente, o traumatismo cranioencefálico leve (escore na ECGla entre 13 e 15) é menos valorizado pelos familiares e pelos próprios profissionais da área médica, correspondendo a 74,5\% dos TCE atendidos no Pronto-socorro de Neurocirurgia da Divisão de Clínica Neurocirúrgica do HC-FMUSP. Muitos desses pacientes não são avaliados ou tratados por médicos. Apenas 2,5\% dos pacientes, em ECGla $=15$, têm alto risco e acabam desenvolvendo lesões de cunho neurocirúrgico. Até recentemente, a maioria dos trabalhos da literatura tinham o enfoque voltado ao TCE moderado e grave $($ ECGla $<12)$, proporcionando um melhor entendimento da epidemiologia, fisiopatologia e tratamento desses pacientes. Embora o paciente com TCE leve apresente, habitualmente, exame físico e neurológico normal, análise mais cuidadosa de suas funções cognitivas, mais especificamente da memória, atenção, orientação, afetividade e personalidade, pode demonstrar acometimentos de 
graus variáveis, constituindo sintomas da síndrome pósconcussional e pós-traumática, o que acarretam importantes problemas sociais e familiares, com elevados custos para a sociedade.

Os traumatismos cranianos são muito freqüentes na população infantil, sendo que a maioria não requer atendimento médico. Esses traumatismos constituem grande preocupação aos pediatras, neurocirurgiões, neurologistas e médicos que lidam com emergência, visto que mesmo os traumatismos aparentemente leves podem apresentar complicações intracranianas que acarretam piora do estado clínico da criança e culminam com o falecimento. A principal preocupação médica nos TCE, na criança, é que uma lesão expansiva não seja inicialmente menosprezada e analisada superficialmente.

Ressalte-se, em nosso meio, o aumento considerável da incidência de espancamento infantil, que deve ser rigorosamente pesquisado, identificando-se a origem dos TCE, nas crianças que são negligenciadas por seus familiares e/ou pessoas que são incumbidas de protegê-las.

A nova abordagem deve voltar-se não apenas ao atendimento, mas também, e preferencialmente, à prevenção do TCE (Think First Program). Programas de conscientização capazes de prover à sociedade maior conhecimento da fisiopatologia e dos mecanismos de traumatismos cranianos devem ser instituídos com programas de prevenção geral como o cumprimento às leis de trânsito e campanhas de desarmamento, gerando grande benefício pessoal e econômico à sociedade. Acreditamos que a prevenção eficaz necessita da atuação governamental, instituindose legislação que proíba o uso de arma de fogo pela sociedade e controle o consumo de bebidas alcóolicas e drogas em todas as faixas etárias e níveis sociais. Essas são as diretrizes do Departamento de Trauma da Sociedade Brasileira de Neurocirurgia para o ano 2000. 


\section{DIRETRIZES DO ATENDIMENTO PRÉ-HOSPITALAR AO PACIENTE COM TRAUMATISMO CRANIOENCEFÁLICO}

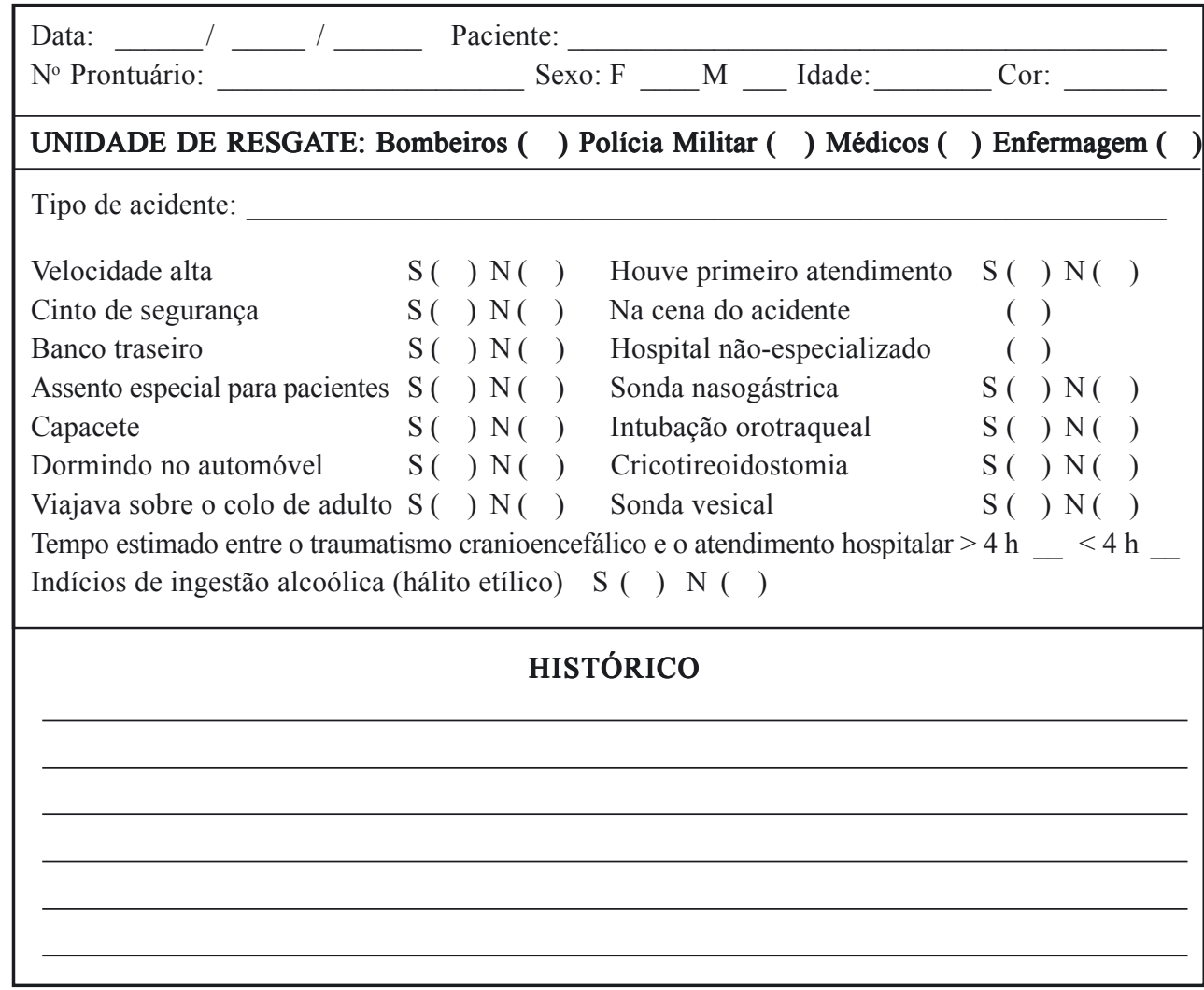

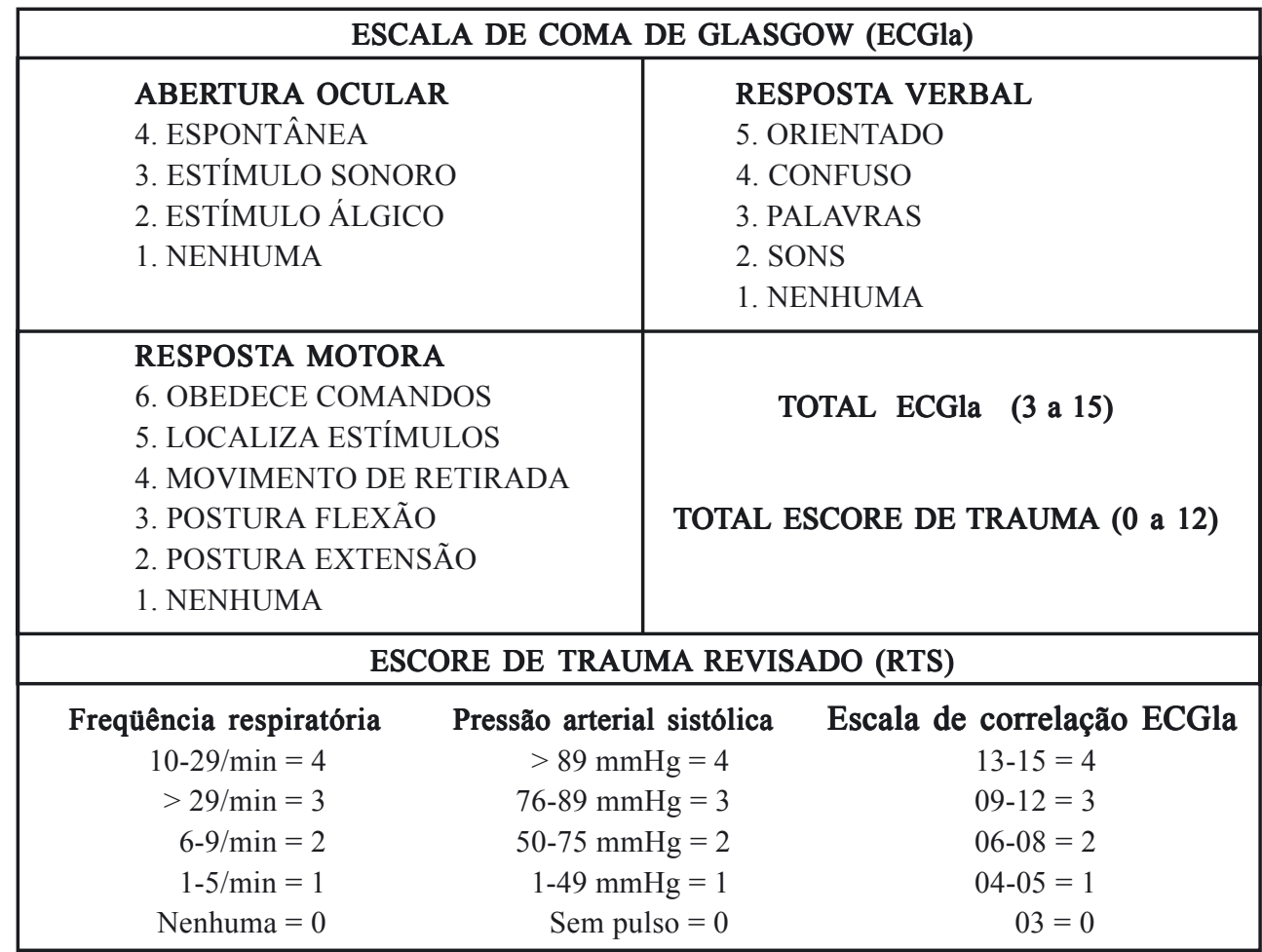




\section{1 - Atendimento Primário}

A. Manobras básicas para assegurar e manter a desobstrução das vias aéreas:
a) 1. tração do mento;
2. elevação da mandíbula;
3. cânula orofaríngea (Guedell);
4. aspiração das vias aéreas.

b) abordagem definitiva das vias aéreas (intubação orotraqueal ou cricotireoidostomia por punção).

c) proteção da coluna cervical.

B. Ventilação com AMBU (ou BIRD se disponível na unidade de resgate).

C. Normalização dos parâmetros hemodinâmicos, utilizando-se solução cristalóide. Sangue e drogas vasoativas em casos especiais (por ex.: trauma raquimedular).

D. AVPU (alert, vocalization, pupils e uncounsciousness): avaliação do nível de consciência (ECGla), padrão pupilar e déficit motor lateralizado de extremidade. Habitualmente, um paciente com anormalidades desses três componentes é portador de lesão expansiva que pode requerer tratamento cirúrgico.

E. Exposição: despir e observar todo o paciente (cuidado com hipotermia, uso de manta térmica).

\section{2 - Padrão pupilar}

Reflexo fotomotor

Pupila miótica

Pupila midriática

Pupila médio fixa

Pupilas isocóricas

Pupilas anisocóricas

$\begin{array}{lll} & \text { D } & \text { E } \\ \text { Presente } & (\text { ) } & (\text { ) } \\ \text { Ausente } & (\text { ) } & (\text { ) } \\ & (\text { ) } & (\text { ) } \\ & (\text { ) } & (\text { ) } \\ & (\text { ) } & (\text { ) } \\ & (\text { ) } \\ \text { D }<\text { E } & (\text { ) } \\ \text { D }>\text { E } & (\text { ) }\end{array}$

\section{3 - Déficit motor}

Hemiparesia

Paraparesia

\section{( ) Monoparesia}

( ) Tetraparesia

\begin{tabular}{|c|c|c|}
\hline \multirow{5}{*}{$\begin{array}{l}\left(\begin{array}{l}) \\
(\end{array}\right) \\
\end{array}$} & \multirow{5}{*}{$\begin{array}{c}\text { DÉFICIT DE } \\
\text { FORÇA } \\
\text { MUSCULAR }\end{array}$} & $F A C E$ \\
\hline & & MEMBROSUPERIOR \\
\hline & & 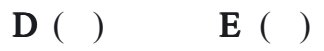 \\
\hline & & MEMBRO INFERIOR \\
\hline & & $\mathbf{D}\left(\begin{array}{l}\mathrm{E}(\mathrm{l}) \\
\end{array}\right.$ \\
\hline
\end{tabular}

\section{4 - Critérios de gravidade neurológica para transferência ao hospital especializado}

1. Diminuição de pontuação na escala de Glasgow.

2. Diminuição de pontuação na escore de trauma (RTS).

3. Pupilas anisocóricas ou sem reflexo fotomotor.

4. Surgimento ou piora de déficit motor.

5. Hipotensão ou aumento progressivo da pressão arterial sistêmica.

6. Aumento dehematoma subgaleal do couro cabeludo.

7. Irregularidade respiratória.

8. Convulsão

9. Ferimento penetrante de crânio.

10. Fístula liquórica (rino e/ou otoliquorréa).

11. Surgimento de cefaléia, náuseas, vômitos e sonolência. 


\section{DIRETRIZES DO ATENDIMENTO HOSPITALAR AO PACIENTE COM TRAUMATISMO CRANIOENCEFÁLICO}

Data: ___ _ _ _ Paciente:

$\mathrm{N}^{\circ}$ Prontuário:

Sexo: F

M

Idade:

Cor:

Tipo de acidente:

Houve primeiro atendimento: $\mathrm{S}(\mathrm{N}) \mathrm{N}($ )

Na cena do acidente: ( ) Hospitalar não-especializado: ( )

Tempo estimado entre o traumatismo cranioencefálico e o atendimento hospitalar: $>4 \mathrm{~h} \_<4 \mathrm{~h}$

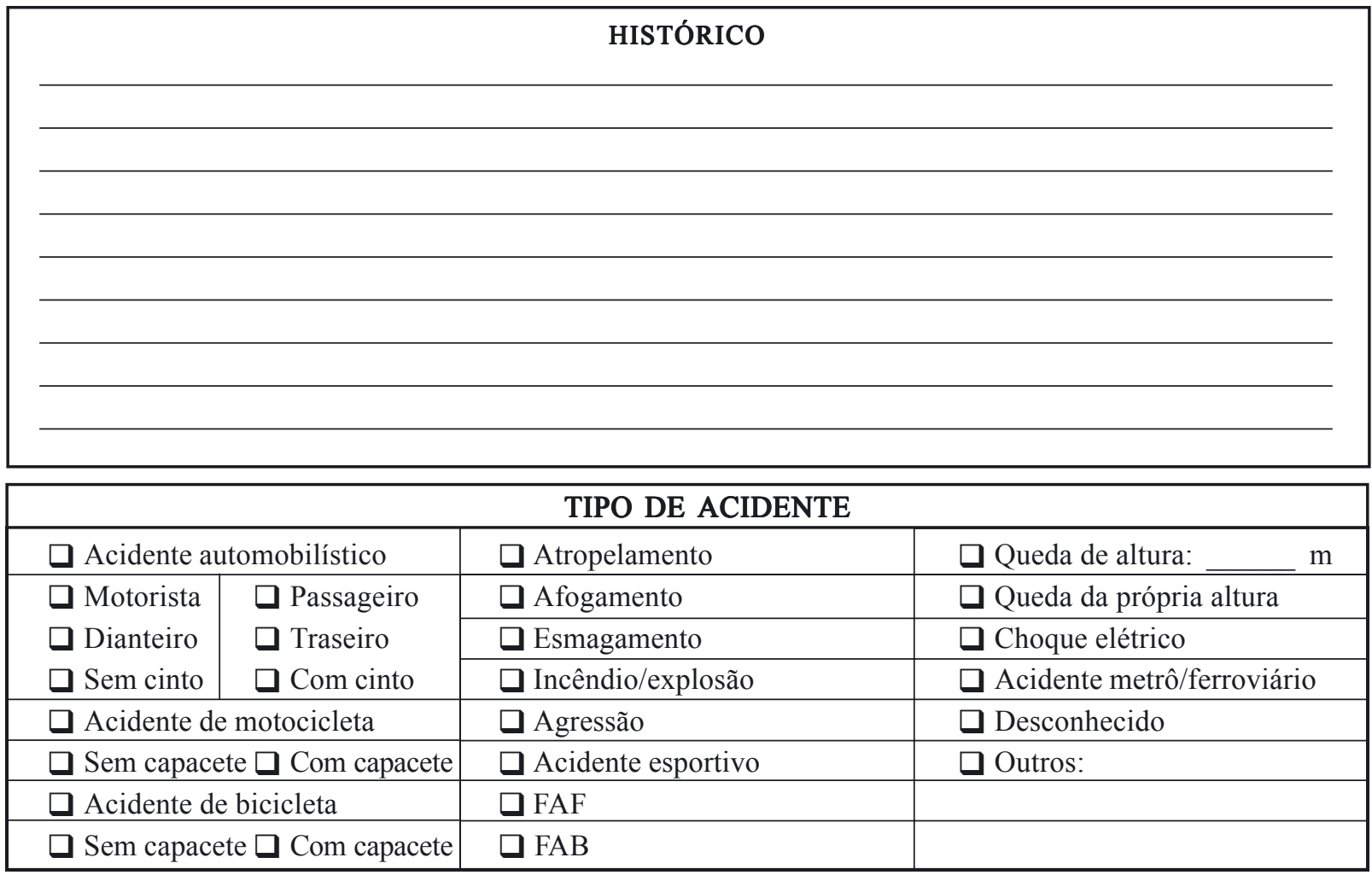

\begin{tabular}{|c|c|}
\hline \multicolumn{2}{|c|}{ ESCALA DE COMA DE GLASGOW (ECGla) PARA MAIORES DE 5 ANOS DE IDADF } \\
\hline $\begin{array}{l}\text { ABERTURA OCULAR } \\
\text { 4. ESPONTÂNEA } \\
\text { 3. ESTÍMULO SONORO } \\
\text { 2. ESTÍMULO ÁLGICO } \\
\text { 1. NENHUMA }\end{array}$ & $\begin{array}{l}\qquad \text { RESPOSTA VERBAL } \\
\text { 5. ORIENTADO } \\
\text { 4. CONFUSO } \\
\text { 3. PALAVRAS } \\
\text { 2. SONS } \\
\text { 1. NENHUMA }\end{array}$ \\
\hline $\begin{array}{l}\text { RESPOSTA MOTORA } \\
\text { 6. OBEDECE AOS COMANDOS } \\
\text { 5. LOCALIZA ESTÍMULOS } \\
\text { 4. MOVIMENTO DE RETIRADA } \\
\text { 3. POSTURA FLEXÃO } \\
\text { 2. POSTURA EXTENSÃO } \\
\text { 1. NENHUMA }\end{array}$ & $\begin{array}{l}\text { TOTAL ECGla }(3 \text { a } 15)= \\
\text { TOTAL ESCORE DE } \\
\text { TRAUMA }(0 \text { a 12) }=\end{array}$ \\
\hline
\end{tabular}




\begin{tabular}{|c|c|c|}
\hline \multicolumn{2}{|c|}{ ESCORE DE TRAUMA REVISADO (RTS) } \\
\hline Freqüência respiratória & Pressão arterial sistólica & Escala de correlação ECGla \\
$10-29 / \mathrm{min}=4$ & $>89 \mathrm{mmHg}=4$ & $13-15=4$ \\
$>29 / \mathrm{min}=3$ & $76-89 \mathrm{mmHg}=3$ & $09-12=3$ \\
$6-9 / \mathrm{min}=2$ & $50-76 \mathrm{mmHg}=2$ & $06-08=2$ \\
$1-5 / \mathrm{min}=1$ & $1-49 \mathrm{mmHg}=1$ & $04-05=1$ \\
Nenhuma $=0$ & Sem pulso $=0$ & $03=0$ \\
\hline
\end{tabular}

\begin{tabular}{|c|c|c|}
\hline \multicolumn{2}{|c|}{ ESCALA DE COMA DE GLASGOW PARA PACIENTES DE 1 A 4 ANOS DE IDADE } \\
\hline Resposta & Forma & Escore \\
\hline Abertura ocular & Espontânea & 3 \\
& Ordem verbal & 2 \\
& Estímulo doloroso & 1 \\
\hline Melhor resposta verbal & Sem resposta & 5 \\
& Balbucio & 4 \\
& Choro irritado & 3 \\
& Choro por estímulo doloroso & 2 \\
\hline Melhor resposta motora & Gemido a dor & 1 \\
& Sem resposta & 6 \\
& Movimento espontâneo normal & 5 \\
& Localiza estímulos & 4 \\
& Reage à dor & 3 \\
& Decorticação & 2 \\
\hline TOTAL & Descerebração & 1 \\
\hline
\end{tabular}

\begin{tabular}{|c|c|}
\hline \multicolumn{2}{|c|}{ ESCALA DE COMA DE GLASGOW PARA PACIENTES DE 1 A 12 MESES DE IDADE } \\
\hline 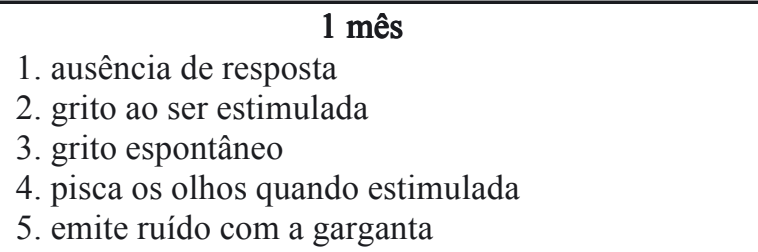 & $\begin{array}{l}\qquad 5 \text { e } 6 \text { meses } \\
\text { 1. ausência de resposta } \\
\text { 2. grito ao ser estimulada (gemido) } \\
\text { 3. localiza a direção dos sons } \\
\text { 4. reconhece pessoas da família } \\
\text { 5. balbucio para pessoas, brinquedos }\end{array}$ \\
\hline \begin{tabular}{l}
\multicolumn{1}{c}{2 meses } \\
1. ausência de resposta \\
2. grito ao ser estimulada \\
3. fecha os olhos com estímulo luminoso \\
4. sorri quando acariciada \\
5. balbucio - apenas sons de vogais
\end{tabular} & $\begin{array}{l}\text { 7 e } 8 \text { meses } \\
\text { 1. ausência de resposta } \\
\text { 2. grito ao ser estimulada (gemido) } \\
\text { 3. reconhece a família e as vozes familiares } \\
\text { 4. balbucio } \\
\text { 5. "ba", "ma", "dada" }\end{array}$ \\
\hline \begin{tabular}{l}
\multicolumn{1}{c}{3 meses } \\
1. ausência de resposta \\
2. grito ao ser estimulada \\
3. fixa o olhar ao ser estimulada, olhando também \\
o ambiente \\
4. sorriso à estimulação sonora \\
5. riso disfarçado - sons semelhantes ao de pombo
\end{tabular} & $\begin{array}{l}\qquad 9 \text { e } 10 \text { meses } \\
\text { 1. ausência de resposta } \\
\text { 2. grito ao ser estimulada } \\
\text { 3. reconhece por meio de sorriso ou risada } \\
\text { 4. balbucio } \\
\text { 5. "mama", "dada" }\end{array}$ \\
\hline $\begin{array}{l}\text { 4 meses } \\
\text { 1. ausência de resposta } \\
\text { 2. grito ao ser estimulada } \\
\text { 3. vira a cabeça ao estímulo sonoro } \\
\text { 4. sorri espontaneamente ou quando estimulada, } \\
\text { risada quando socialmente estimulada } \\
\text { 5. modulação da voz e vocalização correta de vogais }\end{array}$ & $\begin{array}{l}\text { 11 e } 12 \text { meses } \\
\text { 1. ausência de resposta } \\
\text { 2. grito ao ser estimulada (gemido) } \\
\text { 3. reconhece por meio de sorriso } \\
\text { 4. balbucio } \\
\text { 5. palavras (especificamente "mama", "dada") }\end{array}$ \\
\hline
\end{tabular}




\section{CONDUTAS BÁSICAS NO ATENDIMENTO AO PACIENTE COM TRAUMATISMO (ATLS - ADVANCED TRAUMA LIFE SUPORT)}

\section{1 - Atendimento primário}

A. Manobras básicas de desobstrução das vias aéreas:

a) 1. vias aéreas pérvias;

2. tração do mento;

3. elevação da mandíbula;

4. cânulas orofaríngea (Guedell) e nasofaríngea;

5. aspiração das vias aéreas.

b) abordagem definitiva das vias aéreas: intubação orotraqueal, abordagem cirúrgica das vias aéreas (cricotireoidostomia por punção ou cirurgia).

c) proteção da coluna cervical.

d) colocar travesseiro sob os ombros, para evitar a hiperextensão cervical.

B. Ventilação: normal ou hiperventilação leve, até três horas.

C. Normalização dos parâmetros hemodinâmicos utilizando-se solução cristalóide, sangue e drogas vasopressoras em casos especiais (trauma raquimedular).

D. Avaliação neurológica: ECGla, padrões pupilar e respiratório, déficit motor e reflexos.

E. Exposição: despir e observar todo o paciente, cuidado com hipotermia (manta de aquecimento).

\section{2 - Reanimação}

A. Estabilização cervical: manter colar fixo até a avaliação clínica, neurológica e radiológica, se apresentar dor ao exame físico ou pela anamnese.

B. Assegurar boas condições ventilatórias: ventilação mecânica, oxigenioterapia.

C. Diagnosticar e tratar: obstrução de vias aéreas, pneumotórax hipertensivo ou aberto, hemotórax maciço, tórax instável, tamponamento cardíaco.

D. Suporte circulatório e controle da hemorragia: tratar o choque agressivamente para melhorar a perfusão tecidual.

E. Reavaliar a resposta à reanimação: pulso, pressão arterial, perfusão capilar periférica e débito urinário.

F. Sonda nasogástrica se não houver contra-indicação como suspeita de fratura de base de crânio ou fístula liquórica nasal e sonda vesical, se não houver suspeita de lesão da uretra ou lesão perineal (toque retal).

G. Lavagem peritoneal diagnóstica ou ultra-sonografia nos pacientes com instabilidade hemodinâmica, com TCE ou com traumatismo raquimedular.

H. Avaliação ortopédica de imediato para limpeza cirúrgica e fixação das fraturas.

I. Diagnóstico radiológico das lesões associadas: RX da coluna cervical, RX tórax, bacia e membros.

\section{3 - Avaliação secundária do paciente hemodinamicamente estável}

A. Radiografia simples de crânio, somente em pacientes com escore 15 na ECGla, a critério médico, após consulta para liberação ou que, após período de observação (12 horas), apresentem exame físico e neurológico normais. Com RX normal, recebe a folha de orientação ao paciente com TCE.

B. Tomografia computadorizada de crânio com janela para osso em todos os pacientes que preencham os critérios para a admissão pelo TCE, ou ultra-sonografia transcraniana.

C. Doppler transcraniano e das carótidas internas, após avaliação da tomografia de crânio.

D. Angiografia cerebral convencional ou digital quando sugestivo de lesões vasculares.

E. Ressonância magnética em pacientes com sinais neurológicos focais ou difusos, com TC normal ou mostrando pequenas lesões que necessitem de acompanhamento mais fidedigno.

F. Angiografia cerebral por ressonância, para o diagnóstico de lesões de seios venosos ou arteriais em situações especiais em que o paciente não pode ser submetido à angiografia. 


\section{SINAIS NEUROLÓGICOS DE LOCALIZAÇÃO}

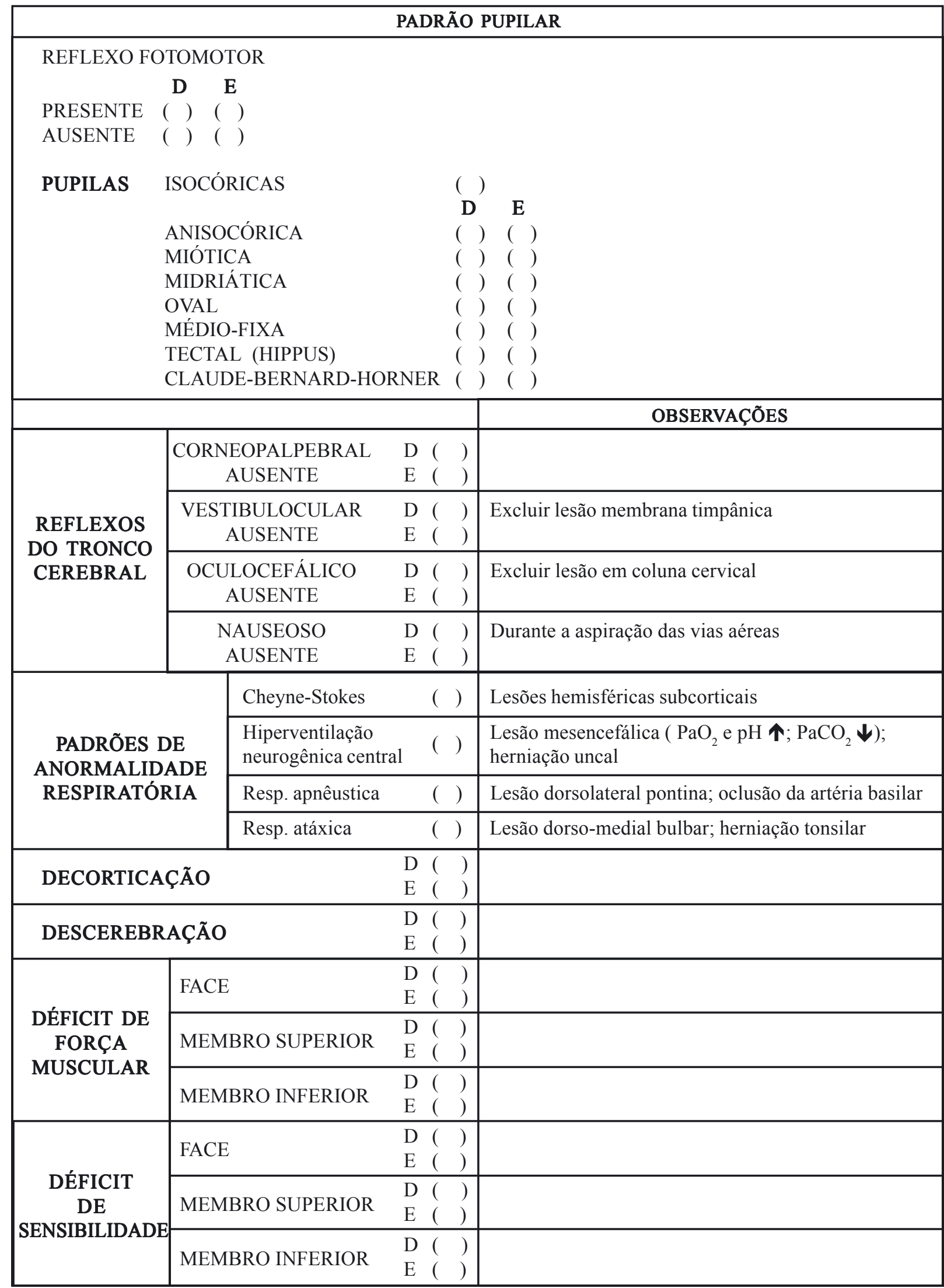


EXAMES DE IMAGEM

\begin{tabular}{|c|c|c|c|c|c|c|}
\hline \multicolumn{7}{|c|}{ RADIOGRAFIA SIMPLES DE CRÂNIO } \\
\hline \multirow{2}{*}{ FRATURA } & AUSENTE & ( ) & LINEAR & ( ) & COMINUTIVA & ( ) \\
\hline & AFUNDAMENTO & ( ) & EXPOSTA & $($ ) & PERFURANTE & $($ ) \\
\hline \multirow{2}{*}{ LOCALIZAÇÃO } & FRONTAL & ( ) & TEMPORAL & ( ) & PARIETAL & ( ) \\
\hline & OCCIPITAL & ( ) & SEIO SAGITAL & $($ ) & SEIO TRANSVERSO & $($ ( ) \\
\hline
\end{tabular}

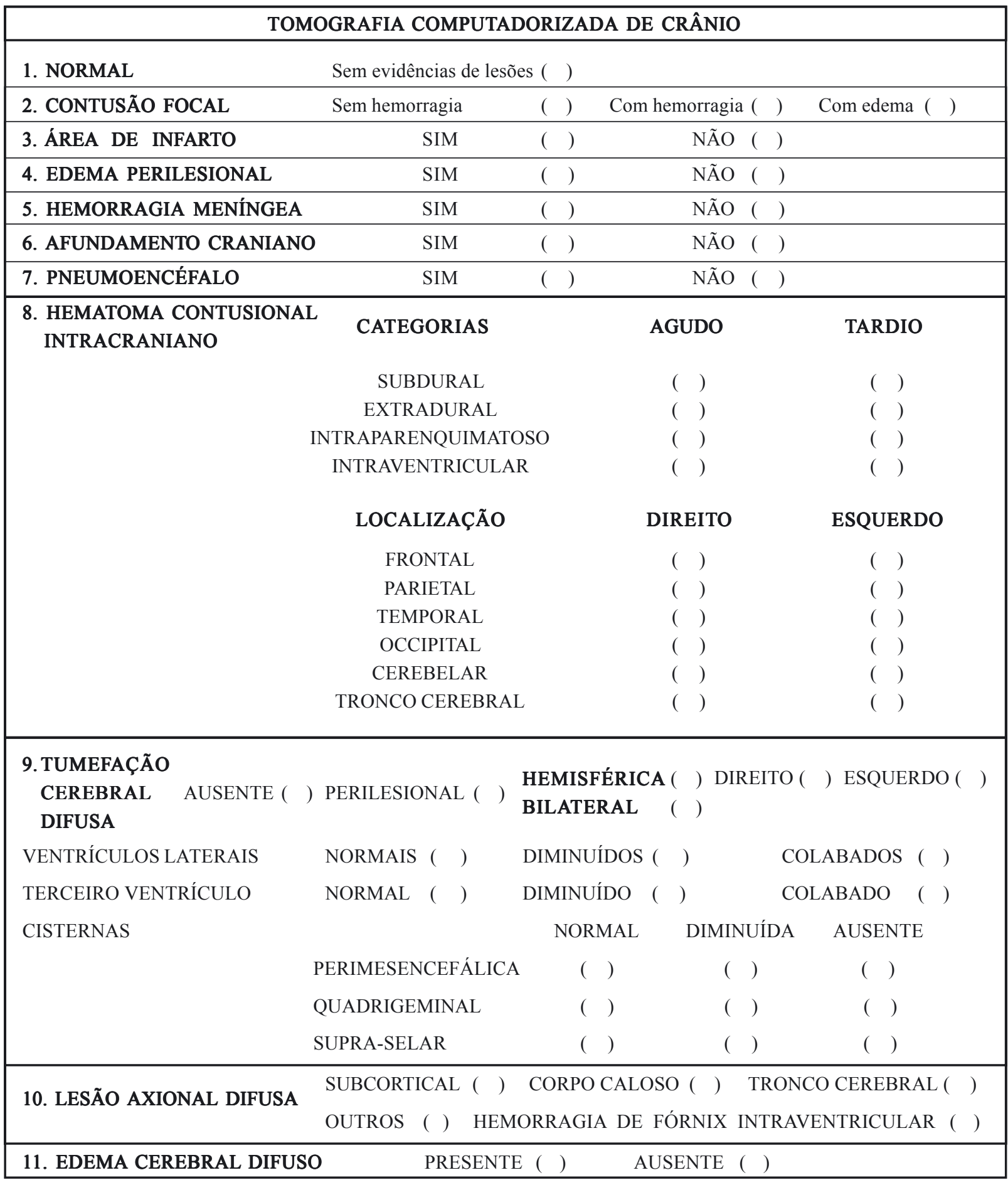




\begin{tabular}{|c|c|}
\hline \multicolumn{2}{|c|}{$\begin{array}{l}\text { CONDUTA POR DESVIO DAS ESTRUTURAS DA LINHA MÉDIA (DLM) } \\
\text { RELAÇÃO COM O NÍVEL DE CONSCIÊNCIA }\end{array}$} \\
\hline \multicolumn{2}{|c|}{$\begin{array}{c}\leq 5 \mathrm{~mm}=\text { depende do quadro clínico e do volume } \\
6 \mathrm{~mm}-14 \mathrm{~mm}=\text { depende do quadro clínico ou da PIC } \\
\geq 15 \mathrm{~mm}=\text { cirurgia, independente do quadro clínico ou da PIC }\end{array}$} \\
\hline $\begin{array}{l}\leq 5 \mathrm{~mm} \\
6 \mathrm{~mm}-14 \mathrm{~mm} \text { e ECGla } \\
6 \mathrm{~mm}-14 \mathrm{~mm} \text { e ECGla } \\
\geq 15 \mathrm{~mm}\end{array}$ & $\begin{array}{c}\text { MONITORIZAÇÃO DA PIC } \\
\text { MONITORIZAÇÃO DA PIC } \\
\text { CIRURGIA E MONITORIZAÇÃO DA PIC } \\
\text { CIRURGIA E MONITORIZAÇÃO DA PIC }\end{array}$ \\
\hline \multicolumn{2}{|c|}{$\begin{array}{l}\text { CONDUTA POR VOLUME DO HEMATOMA OU CONTUSÃO } \\
\text { VOLUME ELIPSÓIDE }=4 / 3 \pi \text {.A.B.C. }\end{array}$} \\
\hline INFRATENTORIAL & SUPRATENTORIAL \\
\hline $\begin{array}{c}\leq 16 \mathrm{~cm}^{3}=\text { não cirúrugico }(\text { ou derivação para hidrocefalia }) \\
>16 \mathrm{~cm}^{3}=\text { cirúrgico } \\
>23 \mathrm{~cm}^{3}=\text { mortalidade elevada }\end{array}$ & $\begin{array}{c}\leq 30 \mathrm{~cm}^{3}=\text { não-cirúrgico } \\
>30 \mathrm{~cm}^{3}=\text { cirúrgico } \\
>50 \mathrm{~cm}^{3}=\text { mortalidade elevada }\end{array}$ \\
\hline
\end{tabular}

\section{PACIENTES CONSCIENTES (ECGla $=15)$ CRITÉRIOS PARA ADMISSÃO OU OBSERVAÇÃO}

1. Radiografias simples do crânio, da coluna cervical após avaliar mecanismo de trauma e outras, quando necessárias.

2. Tomografia computadorizada de crânio, se os CRITÉRIOS PARA ADMISSÃO ou OBSERVAÇÃO estiverem presentes.

\section{CRITÉRIOS PARA ADMISSÃO (ALTO RISCO)}

\section{A) Físicos:}

1. Equimose orbitopalpebral ou retroauricular.

2. Lesão de envoltórios do crânio.

3. Saída de LCR, através ouvido ou nariz.

4. Lesão de terceiro nervo craniano.

B) Neurológico, se teve ou tem:

1. Desorientação, amnésia pré ou pós-TCE.

2. Perda da consciência.

3. Cefaléia, náuseas, vômitos ou convulsões.

4. Piora do nível de consciência.

5. Sinais localizatórios, dor na nuca.

6. Plegia facial periférica.

7. Distúrbios cognitivos.

8. Sonolência excessiva.

9. Intoxicação com álcool ou drogas.

\section{C) Critérios radiológicos:}

1. RX simples com fratura de base de crânio e/ou afundamento.

2. Fratura linear craniana com TC alterada.

3. TC de crânio mostrando fratura ou afundamento, mesmo sem lesões intracranianas.

4. TC de crânio mostrando lesões intracranianas ou pneumocrânio.

5. RM de crânio com lesões encefálicas.

6. Hidrocefalia com hemorragia meníngea traumática.

\section{LIBERAÇÃO DO PACIENTE DO CONSULTÓRIO HOSPITALAR OU DA SALA DE OBSERVAÇÃO (BAIXO RISCO)}

1. Sem sinais ou sintomas após análise dos CRITÉRIOS PARA ADMISSÃO.

2. Retornar se apresentar sinais e sintomas presentes na FOLHA DE ORIENTAÇÃO AO PACIENTE COM TCE.

CRITÉRIOS DE OBSERVAÇÃO ATÉ 12 HORAS

$\triangle$ (ALTO RISCO)

1. $\mathrm{ECGla}=15$, história de sintomas neurológicos ou história de acidente grave e/ou com vítimas; RX simples de crânio e TC de crânio normais.

2. $\mathrm{ECGla}=15$, cefaléia, náuseas, vômitos ou convulsões; TC de crânio normal.

3. ECGla $=15$, com ou sem sinais e sintomas neurológicos; RX simples de crânio com fratura linear (sem afundamento) e TC de crânio normal.

4. $\mathrm{ECGla}=15$, adolescente com hálito etílico, náuseas, vômitos ou convulsões; TC de crânio normal.

5. ECGla $=15$, paciente com hidrocefalia, derivada ou não.

6. ECGla $=15$, alteração neuropsicológica, TC de crânio normal.

7. $\mathrm{ECGla}=15$, alterações de exame físico. 


\section{ORIENTAÇÕES AOS FAMILIARES}

Até o momento não pudemos constatar, pelos exames realizados, qualquer evidência de que o traumatismo craniano sofrido pelo paciente tenha sido significativo para que permaneça em OBSERVAÇÃ̃O nesse hospital. Portanto, será LIBERADO. Entretanto, novos sintomas, sinais e complicações inesperados podem ocorrer horas, dias, semanas ou até meses após o traumatismo. As primeiras 24 horas são as mais críticas. É aconselhável que esse PACIENTE permaneça em companhia de alguém confiável, pelo menos durante esse período.

O PACIENTE deve retornar imediatamente ao HOSPITAL ESPECIALIZADO que tenha EQUIPE MÉDICA DE EMERGÊNCIA, se aparecer algum dos sintomas ou sinais abaixo relacionados:

1. Cefaléia;

2. Sonolência excessiva ou insônia;

3. Irritabilidade, ansiedade ou labilidade emocional;

4. Desmaio, fraqueza, diminuição da força nas pernas, na metade do corpo, ou formigamento e adormecimento no corpo;

5. Distúrbio da memória, dificuldade para se concentrar;

6. Distúrbio de personalidade;

7. Confusão mental, dificuldade para falar ou entender;

8. Náuseas, vômitos, tonturas ou convulsão;

9. Diminuição da audição ou intolerância ao som;

10. Movimento estranho dos olhos, visão dupla, diminuição da acuidade visual ou intolerância à luz;

11. Falta de ar, alteração da respiração, febre $\left(\mathrm{T}>37,8^{\circ} \mathrm{C}\right)$;

12. Perda de líquido ou sangue pelo ouvido e nariz;

13. Tamanhos das pupilas diferentes;

14. Quadro depressivo;

15. Qualquer modificação observada durante esse período, aconselhamos retornar ao hospital de origem.

O paciente pode continuar usando outras medicações de rotina, porém, NÃO deve usar sedativos (medicações para dormir, xarope para tosse, ou outras medicações que possam produzir sono), pelo menos durante 48 horas.

Durante o sono, o paciente deve ser acordado freqüentemente, para que se possa avaliar as orientações acima.

Recebi o original em / / 


\section{MONITORIZAÇÃO DA HEMODINÂMICA INTRACRANIANA \\ POR MEIO DE DOPPLER TRANSCRANIANO}

\section{Parâmetros de importância:}

Velocidades de fluxo das artérias intracranianas e das artérias. carótidas internas extracranianas (ACI extracraniana)

Índice de Lindegaard $(\mathrm{IL})=\mathrm{Vm} A C M \div \mathrm{Vm}$ ACI

extracraniana

Índice de pulsatilidade $(I P)=($ Vmáx - Vmín $) \div V m$

Vasorreatividade

- Aumento de $\mathrm{Vm} \mathrm{ACM}_{2}$

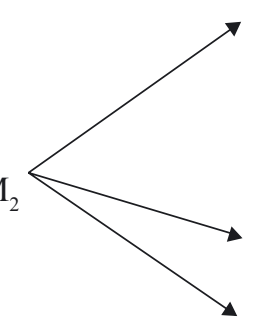

IL $<3$ : - sem vasoespasmo

- hiperemia cerebral

- hemodiluição, anemia, febre

- estado adrenérgico

IL entre 3 e 6: vasoespasmo leve a moderado

IL > 6: vasoespasmo grave

- Diminuição da Vm ACI extracraniana: oligoemia cerebral

- hipovolemia

- aumento significativo de PIC

- bradicardia

- IP elevado:

- aumento da PIC

- infarto cerebral, edema, hematoma

- vasoespasmo da microcirculação cerebral

- IP diminuído:

- PIC normal

- estado de hiperemia cerebral

- fistulização arterial

- vasodilatação da microcirculação cerebral

- Detecção de êmbolos em circulação intracraniana: suspeita de dissecção traumática das artérias carótidas ou vertebrobasilar.

O resultado do exame é obtido por análise destes parâmetros e do quadro clínico do paciente. 


\section{MONITORIZAÇÃO CONTÍNUA DA PRESSÃO INTRACRANIANA}

\section{CRITÉRIOS DE INCLUSÃO}

1. Coma por mais de 6 horas ou paciente que necessite sedação, independentemente dos achados na TC.

2. Lesões encefálicas localizadas não-passíveis de cirurgia imediata pelo volume, área ou DLM.

3. Lesões encefálicas difusas ou focais em pacientes em coma.

4. Após tratamento cirúrgico, em pacientes com sinais e sintomas neurológicos.

5. Em pacientes com lesões vasculares cervicocranianas e TC anormal.

6. Paciente em coma com TC anormal e que necessitam de PEEP (não ultrapassar $5 \mathrm{cmH}_{2} \mathrm{O}$ ).

7. Paciente em coma com doppler transcraniano anormal.

8. Tratamento de ventriculite associada com hidrocefalia pós-traumática.

\section{CRITÉRIOS DE EXCLUSÃO}

1. $\mathrm{ECGla}=15$ sem sinais ou sintomas, mesmo com TC anormal.

2. Fístula de LCR com débito ou presença de pneumocrânio na TC.

3. Lesões intracranianas com indicação de tratamento cirúrgico imediato.

4. Lesões por projétil de arma de fogo ou por arma branca sem sutura acessível da dura-máter.

5. Processo infeccioso no SNC, ou sistêmico, exceto ventriculite com hidrocefalia.

6. Distúrbio de coagulação ou plaquetopenia não-controlados.

\section{MONITORIZAÇÃO DA PRESSÃO INTRACRANIANA E TEMPERATURA CEREBRAL}

METODOLOGIA: Extradural ( ) Ventricular ( ) Subaracnóidea ( ) Intracerebral ( )

Período de monitorização:

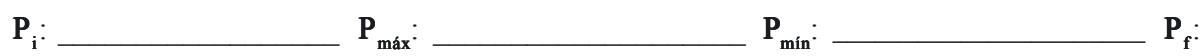

$\mathrm{P}_{\mathrm{i}}=$ Pressão inicial; $\mathrm{P}_{\text {máx }}=$ Pressão máxima; $\mathrm{P}_{\text {min }}=$ Pressão mínima; $\mathrm{P}_{\mathrm{f}}=$ Pressão final

PICm: Pressão intracraniana média permitida $=3 \mathrm{mmHg}$ a $15 \mathrm{mmHg}$

HIPERTENSÃO INTRACRANAIANA: leve $=15 \mathrm{mmHg}-20 \mathrm{mmHg} ;$ moderada $=20 \mathrm{mmHg}-40 \mathrm{mmHg}$; grave $>40 \mathrm{mmHg}$

PRESSÃO DE PERFUSÃO CEREBRAL (PPC): PPC = PAM - PICm

ONDAS DE PRESSÃO INTRACRANIANA: patológicas: A e B (ondas A até $60 \mathrm{mmHg}$ e duração de 5 a 30 minutos, ondas $\mathrm{B}$ com espículas de até $50 \mathrm{mmHg}$ e duração de 0,5 ondas/minuto a 2 ondas/minuto)

CLASSIFICAÇÃO DAS ONDAS: ondas A1, B1: até 20 mmHg; A2, B2: > 20 mmHg

ONDAS DE PULSO DA PIC: P1 = onda de percussão; P2 = onda tidal; P3 = onda dicrótica. Observar a diminuição de $\mathrm{P} 2$ e P3, durante a hiperventilação, o que sugere boa reatividade ao $\mathrm{PCO}_{2}$. 


\section{PACIENTES CONSCIENTES (ECGla $=15$ ), SEM SINTOMAS OU SINAIS NEUROLÓGICOS E/OU NEUROPSICOLÓGICOS, COM TC ALTERADO}

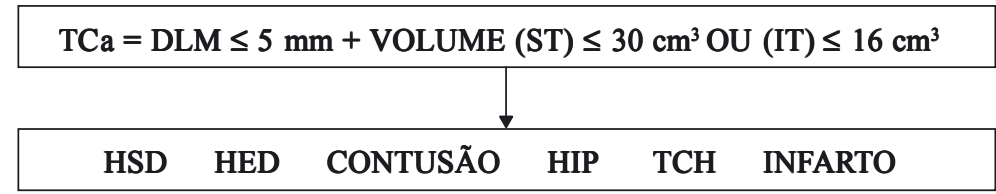

$\left.\begin{array}{ll}\begin{array}{l}1 \text { - HIP } \\ 3 \text { - HSD }\end{array} \\ \begin{array}{l}\text { - }- \text { TCH }+ \text { INFARTO } \\ 6 \text { - CONTUSÃO }\end{array}\end{array}\right\}$ NÃO-CIRÚRGICO

8 - HED (FOSSA MÉDIA OU POSTERIOR)

9 - HED + HSD

10 - HED + HIP

11 - HED + CONTUSÃO

$12-\mathrm{HED}+\mathrm{TCH}$

13 - LACERAÇÃO CEREBRAL + HSD

CIRURGIA $+$

MONITORIZAÇÃO DA PIC

Legenda

ECGla Escala de Coma de Glasgow à admissão

TCa Tomografia de Crânio à admissão

HSD Hematoma Subdural

HED Hematoma Extradural

HIP Hematoma Intraparenquimatoso

TCH Tumefação Cerebral Hemisférica

TF Tumefação Cerebral Focal

ST/IT Supra/Infratentorial

LAD Lesão Axonal Difusa 


\section{PACIENTES CONSCIENTES (ECGla $=15$ ) COM SINAIS OU SINTOMAS NEUROLÓGICOS E/OU NEUROPSICOLÓGICOS}

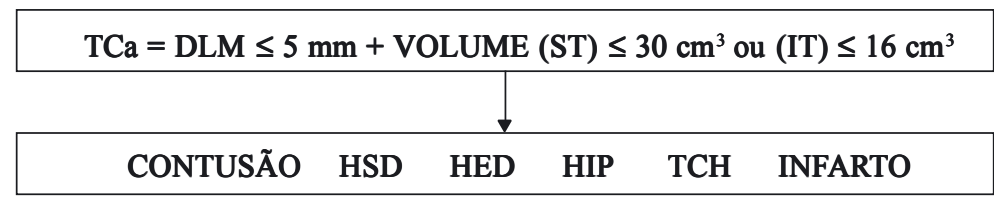
$1-\mathrm{TCH}+\mathrm{HSD}$
$4-\mathrm{TCH}+\mathrm{HIP}$
$2-\mathrm{TCH}+\mathrm{HED}$
$5-\mathrm{TCH}+$ CONTUSÃO
$3-\mathrm{TCH}$
6 - TCH + LACERAÇÃO
7 - HED
8 - HSD

9 - LACERAÇÃO CEREBRAL + HSD

10 - HED (FOSSA MÉDIA OU POSTERIOR)
11 - HIP
12 - CONTUSÃO
13 - INFARTO
14 - CONTUSÃO + TF
15 - HIP + EDEMA PERILESIONAL
$16-\mathrm{HIP}+\mathrm{TF}$

\section{MONITORIZAÇÃO PIC $+$ CRANIOTOMIA E DUROPLASTIA}

CRANIOTOMIA E DUROPLASTIA $+$ MONITORIZAÇÃO PIC (Situações 1, 2, 6, 7, 8 e 10 )

MONITORIZAÇÃO PIC

CRANIOTOMIA

$+$

DUROPLASTIA

Legenda

$\begin{array}{ll}\text { ECGla } & \text { Escala de Coma de Glasgow à admissão } \\ \text { TCa } & \text { Tomografia de Crânio à admissão } \\ \text { HSD } & \text { Hematoma Subdural } \\ \text { HED } & \text { Hematoma Extradural } \\ \text { HIP } & \text { Hematoma Intraparenquimatoso } \\ \text { TCH } & \text { Tumefação Cerebral Hemisférica } \\ \text { TF } & \text { Tumefação Cerebral Focal } \\ \text { ST/IT } & \text { Supra/Infratentorial } \\ \text { LAD } & \text { Lesão Axonal Difusa }\end{array}$




\section{PACIENTES COM 15 PONTOS NA ECGla}

\section{Critérios para admissão}

1. Pacientes que, durante a observação, evoluíram com piora neurológica ou que apresentam lesão intracraniana à TC.

2. Hemiparesia, sem outro sintoma neurológico, TC normal ou apresentando lesão isquêmica.

3. História de acidente grave, sem sinais ou sintomas neurológicos, mas com fístula de LCR, pneumocrânio ou afundamento detectados na TC.

4. Pacientes com alteração neuropsicológica, lesões intracranianas à TC, RM ou SPECT.

5. Sinais ou sintomas de trauma raquimedular, RX de crânio normal, TC ou RM mostrando lesões intracranianas.

\section{PACIENTES COM OU SEM SINTOMAS E SINAIS NEUROLÓGICOS, ECGLA = 15, E QUE PIORAM DURANTE A EVOLUÇÃO (TALK AND DETERIORATE)}

\section{Critérios para admissão}

1. Piora do nível de consciência.

2. Paciente com história de acidente grave, sem sinais ou sintomas neurológicos, com fístula de LCR ou pneumocrânio à TC.

3. Paciente com equimose bipalpebral ou retroauricular, edema ou hematoma de couro cabeludo, ou história de sintomas neurológicos e TC com lesão intracraniana.

4. Paciente com alteração neuropsicológica e TC com lesão intracraniana.

5. Paciente com sinais e sintomas de traumatismo raquimedular, RX de crânio normal e TC com ou sem lesão intracraniana.

6. Paciente com hemiparesia, sem outro sintoma neurológico, com TC normal ou lesão isquêmica.

7. Irregularidade respiratória ou da pressão arterial sistêmica (Escore de Trauma Revisado).

8. Ferimento penetrante de crânio.

\section{Manuseio}

1. Medidas de atendimento inicial (A-B-C-D).

2. Realização imediata de TC. Conduta cirúrgica, se lesão passível de cirurgia imediata.

3. Criança com múltiplas equimoses corporais, sem acompanhante confiável, considerar a hipótese de criança espancada e/ou negligenciada.

4. Criança com alteração do nível de consciência, hemorragia de retina, TC com hemorragia meníngea traumática ou HSD inter-hemisférico, considerar a hipótese de "shaken baby".

5. Hemograma completo, coagulograma completo, dosagem dos níveis séricos de glicose, creatinina, uréia e eletrólitos.

6. RX coluna cervical e, se necessários, de outros segmentos da coluna e de outras regiões.

7. Admitir para observação, mesmo com TC normal.

8. Anticonvulsivantes e antibióticos, quando necessários. 


\section{PACIENTES COM PIORA PROGRESSIVA DA CONSCIÊNCIA, COM MIDRÍASE PARALÍTICA E IRREGULARIDADE RESPIRATÓRIA}

\section{Pacientes com sinais de herniação cerebral}

- Intubação orotraqueal + hiperventilação + manitol 20\% (5 ml/kg IV)

- Craniotomia e/ou medidas de suporte em UTI, se TC mostrar lesão focal ou difusa.

- Se não for disponível TC de imediato: trepanação diagnóstico-terapêutica, frontotemporal inferior (pterium) homolateral à midríase. Se negativa, mesmo procedimento contralateral à midríase.

- Tomografia de crânio, se possível, após o procedimento. Se não, transferência imediata para centro especializado.

- Elevação do decúbito a $30^{\circ}$ (se não houver instabilidade hemodinâmica) e manter a cabeça em posição neutra (sem rotação, flexão ou extensão).

- Thionembutal monitorizado em UTI especializada (se as condições hemodinâmicas permitirem).

- Sem lesões cerebrais visíveis: medidas de suporte em UTI.

- Monitorização da PIC com ou sem temperatura cerebral.

- Doppler transcraniano.

\section{Depois da admissão}

1. Admissão em UTI ou Unidade de Terapia Semi-Intensiva.

2. Exame neurológico repetido.

3. Tomografia de crânio no pós-operatório imediato ou se houver piora neurológica.

4. Doppler transcraniano.

5. Monitorização da pressão intracraniana e temperatura cerebral, se necessário.

6. Angiografia convencional ou por ressonância nas lesões vasculares traumáticas craniocervicais.

7. Depois da alta clínica: orientação para acompanhamento em ambulatório especializado.

Obs.: no TCE, é quase invariável que a PIC exceda os valores normais e, se mantida superior a $60 \mathrm{mmHg}$, a HIC é sempre fatal. A disfunção elétrica cerebral é freqüentemente presente e o fluxo sangüíneo cerebral é comumente alterado quando a PIC está acima de $40 \mathrm{mmHg}$. Valores entre $14 \mathrm{mmHg}$ e $20 \mathrm{mmHg}$ são os mais freqüentemente adotados, a partir dos quais a terapia da hipertensão intracraniana é iniciada no paciente com TCE. 


\section{PACIENTES COM IDADE INFERIOR A 50 ANOS E ECGla = 3-5 ( ); ECGla = 6-8 ( ); ECGla = 9-12 ( ); ECGla $=13-14()$}

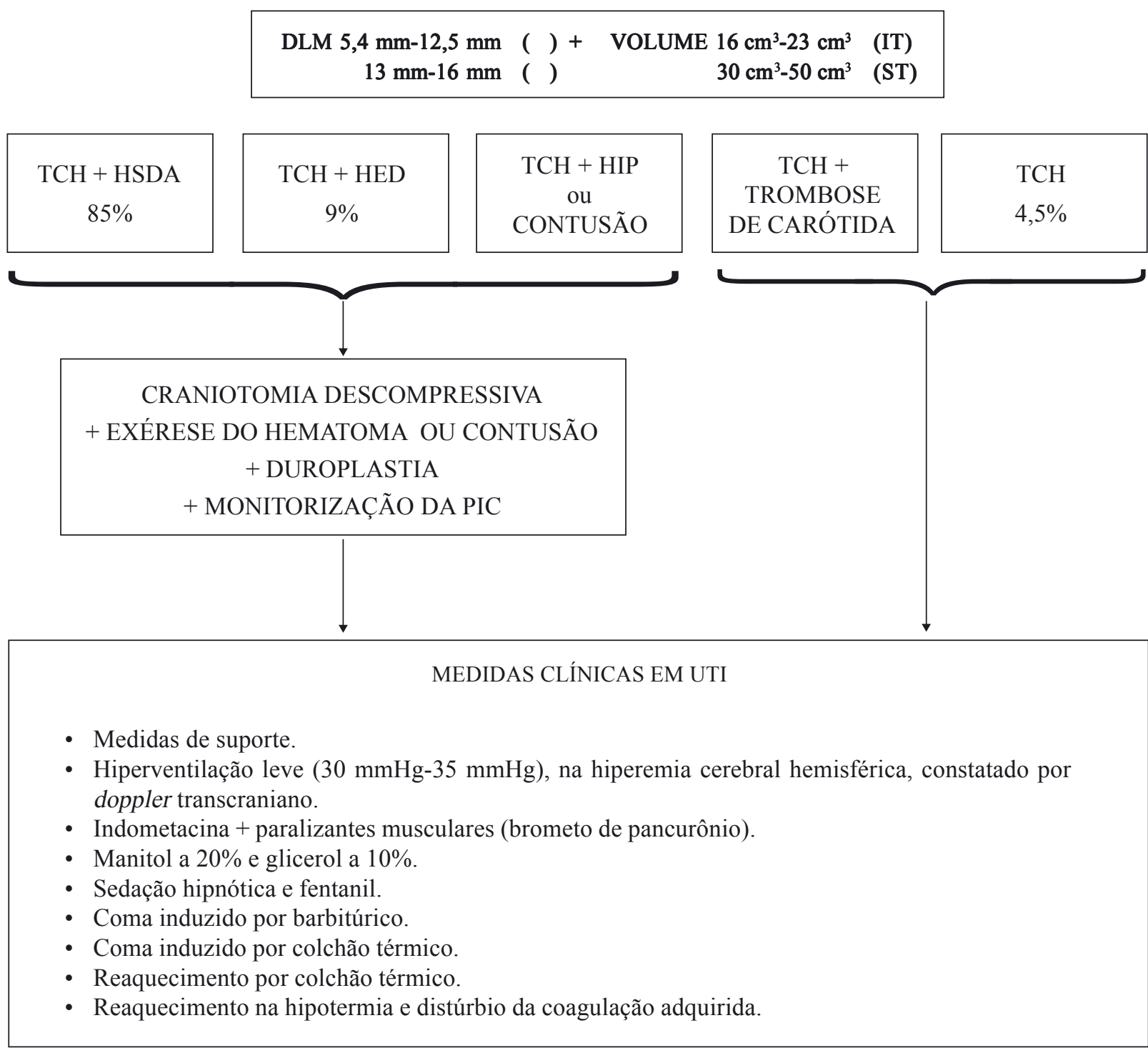




\section{PACIENTES COM IDADE INFERIOR A 50 ANOS, CISTERNAS \\ E VENTRÍCULOS COMPRIMIDOS, HIPEREMIA OU OLIGOEMIA \\ CEREBRAL E ECGla = 3-5 ( ); ECGla = 6-8 ( ); ECGla = 9-12; ECGla = 13-14 ( )}

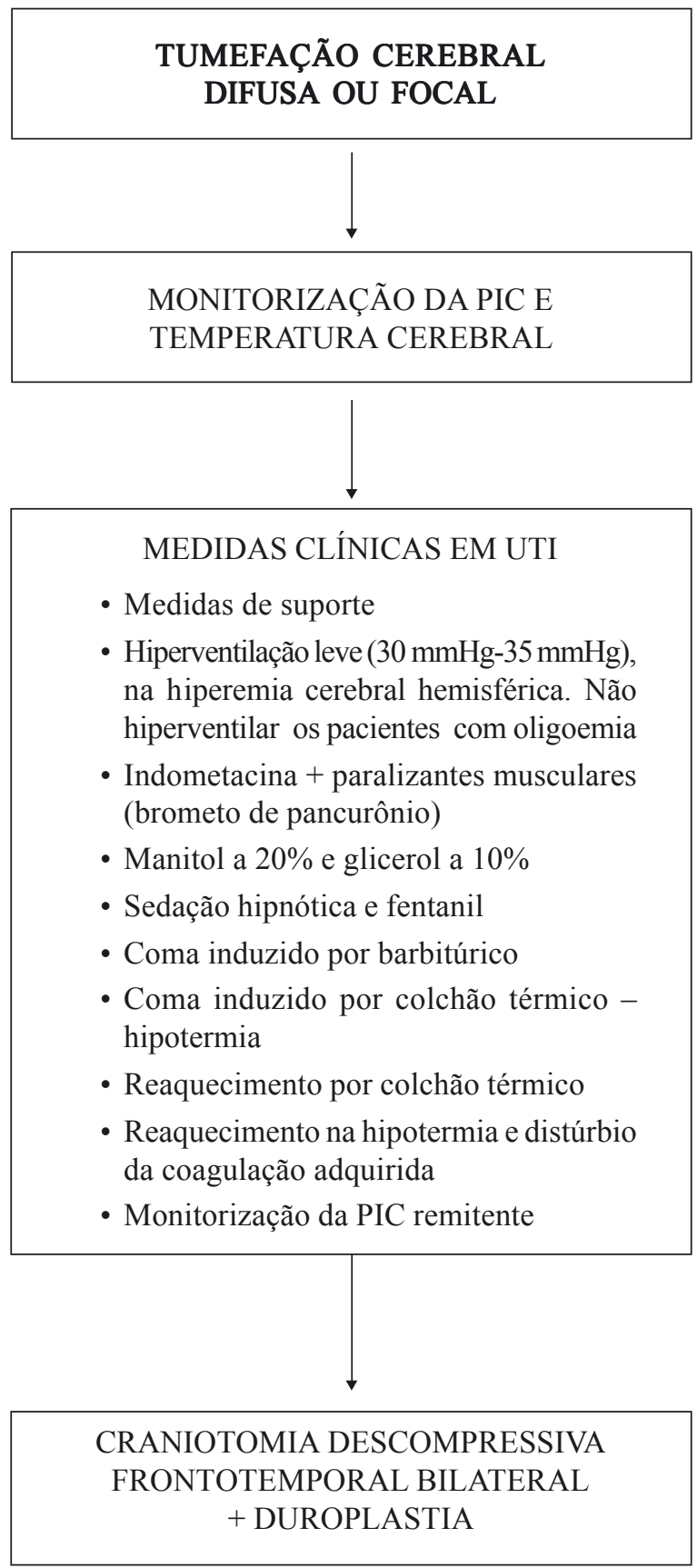

\author{
LESÃO AXONAL DIFUSA \\ LEVE (19\%); MODERADA (45\%); \\ GRAVE (36\%)
}

LAD leve - 6 a 24 horas de coma com recuperação do estado das posturas patológicas; $15 \%$ evoluem para óbito

LAD moderada - período de coma superior a 24 horas com recuperação do nível de consciência, entretanto $24 \%$ evoluem para óbito

LAD grave - período de coma por mais de 24 horas com rara recuperação do nível de consciência; $51 \%$ evoluem para óbito e $7 \%$ para estado vegetativo permanente

1. TC com lesão difusa tipo I

2. TC com lesão hemorrágica subcortical, nos gânglios da base ou em tronco encefálico. Contusões pequenas (gliding contusions) frontoparietas medianas e comissurais (corpo caloso e fórnice)

3. TC com lesão associada; tumefação cerebral difusa e hipertensão intracraniana: monitorização da PIC

4. TC com lesão associada, como hematoma subdural agudo ou hematoma extradural: craniotomia e monitorização de PIC

5. Suporte de base em UTI 


\section{PACIENTES COM TCE GRAVE ASSOCIADO COM CHOQUE HIPOVOLÊMICO}

\section{Grupo I}

ATLS - Paciente com TCE e escore ECGla $\leq 8$, isocórico, com reflexo fotomotor (RFM), presente e simétrico, e choque hipovolêmico que não responde bem à reposição volêmica e medicamentosa e com indicação cirúrgica premente para a causa do choque é encaminhado de imediato ao centro cirúrgico para tratamento da fonte de sangramento.

NEURO - Preconizamos em centro cirúrgico a realização de trepanação diagnóstico-terapêutica temporal inferior direita e monitorização da pressão intracraniana (PIC). Se encontrar-se elevada ( $\geq 20 \mathrm{mmHg}$ ), procede-se trepanação temporal contralateral e, se disponível, estudo por ultra-sonografia na sala. Após a cirurgia para a causa da descompensação hemodinâmica, realiza-se tomografia de crânio para a conduta neurocirúrgica definitiva.

\section{Grupo II}

ATLS - Paciente com TCE, independentemente da ECGla, com midríase paralítica e em choque hipovolêmico que não responde bem à reposição volêmica e medicamentosa, com indicação cirúrgica para a causa do choque, é encaminhamento imediatamente ao centro cirúrgico para controle da fonte de sangramento.

NEURO - Preconizamos em centro cirúrgico trepanação diagnóstico-terapêutica e/ou craniotomia exploratória homolaterais à midríase; se negativa, monitoriza-se a pressão intracraniana e realiza-se o mesmo procedimento cirúrgico contralateralmente. Após a cirurgia para a causa da descompensação hemodinâmica, realiza-se a tomografia de crânio e a conduta neurocirúrgica definitiva.

\section{Grupo III}

ATLS - Paciente com TCE, apresentando pupilas médio-fixas ou midriáticas bilateralmente, em choque hipovolêmico que não respondeu bem ao tratamento específico, com indicação cirúrgica para a causa do choque, é encaminhado de imediato ao centro cirúrgico para controle da fonte de sangramento.

NEURO - Em centro cirúrgico, trepanação diagnóstico-terapêutico bitemporal e/ou craniotomia diante da presença de hematoma e monitorização da PIC. Após a cirurgia para a causa de descompensação hemodinâmica, realiza-se tomografia de crânio e conduta neurocirúrgica definitiva.

\section{Grupo IV}

ATLS -Consiste em todos os grupos anteriores, mas que responderam bem ao tratamento clínico específico para o choque hipovolêmico ou que foram admitidos sem alterações hemodinâmicas.

NEURO - Todos deverão ser submetidos à avaliação neurocirúrgica na sala de admissão e submetidos à tomografia de crânio, realizando-se as condutas neurocirúrgicas necessárias imediatamente após, e monitorização de PIC.

\section{Grupo V}

ATLS TM - Pacientes com TCE, independentemente da pontuação da ECGla com sinais clínicos de trauma raquimedular, em choque refratário ao tratamento específico com ultra-sonografia e/ou lavagem peritoneal diagnóstica positiva, são encaminhados imediatamente ao centro cirúrgico para controle da fonte de sangramento.

NEURO - Com sinais neurológicos idênticos aos grupos citados anteriormente, serão tomadas as mesmas condutas neurocirúrgicas para o TCE. Quando o paciente for estabilizado do ponto de vista hemodinâmico e dopaminérgico, será submetido à cirurgia específica do trauma raquimedular. Se a lavagem peritoneal diagnóstica for negativa, a cirurgia do trauma raquimedular será realizada somente após o equilíbrio hemodinâmico e dopaminérgico em UTI. 


\section{AFUNDAMENTO DE CRÂNIO}

EXAMES DE RAIOS X SIMPLES DE CRÂNIO OU TC COM JANELA ÓSSEA

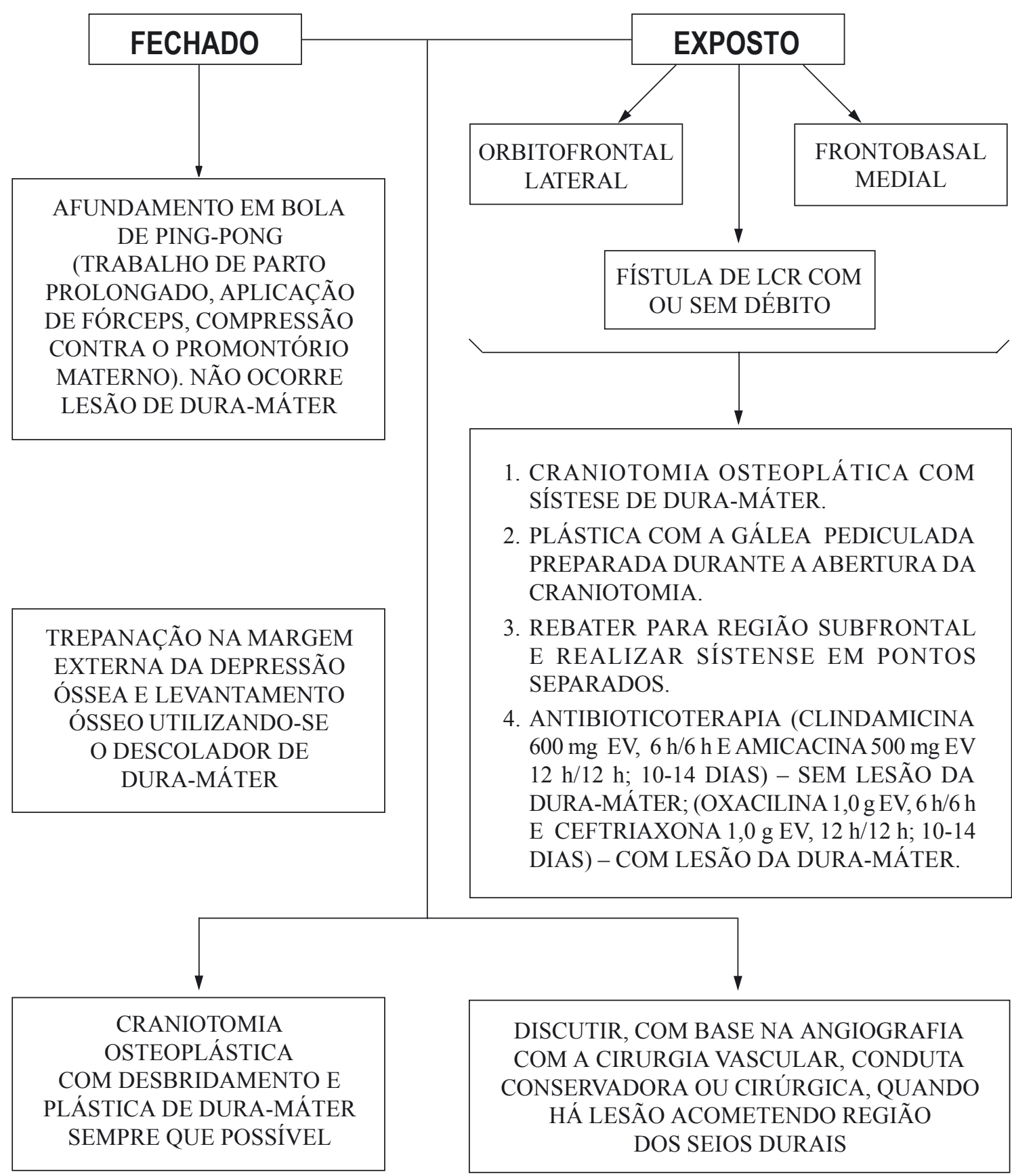




\section{FERIMENTO POR PROJÉTIL DE ARMA DE FOGO}
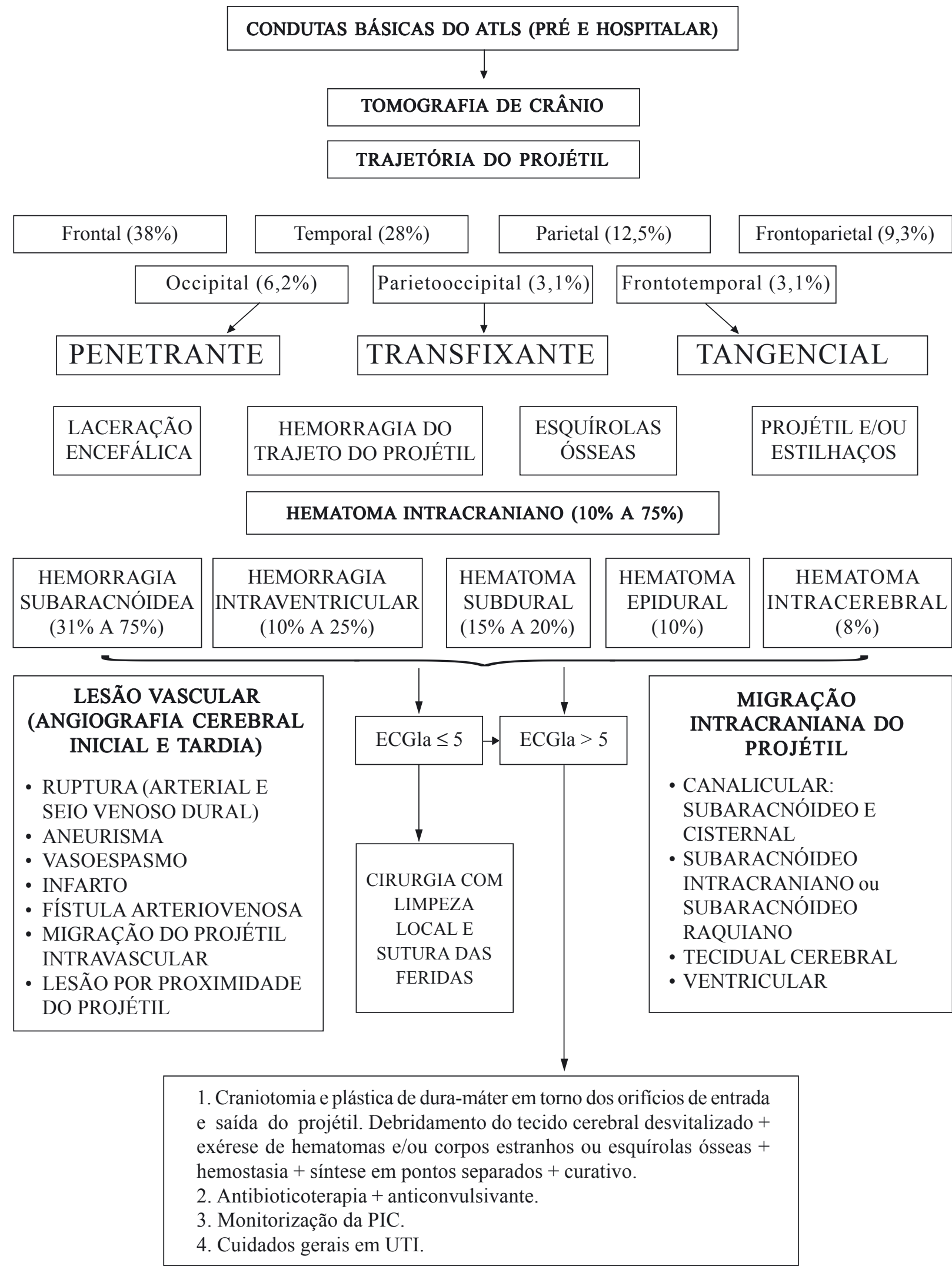


\section{FERIMENTOS POR ARMA BRANCA}

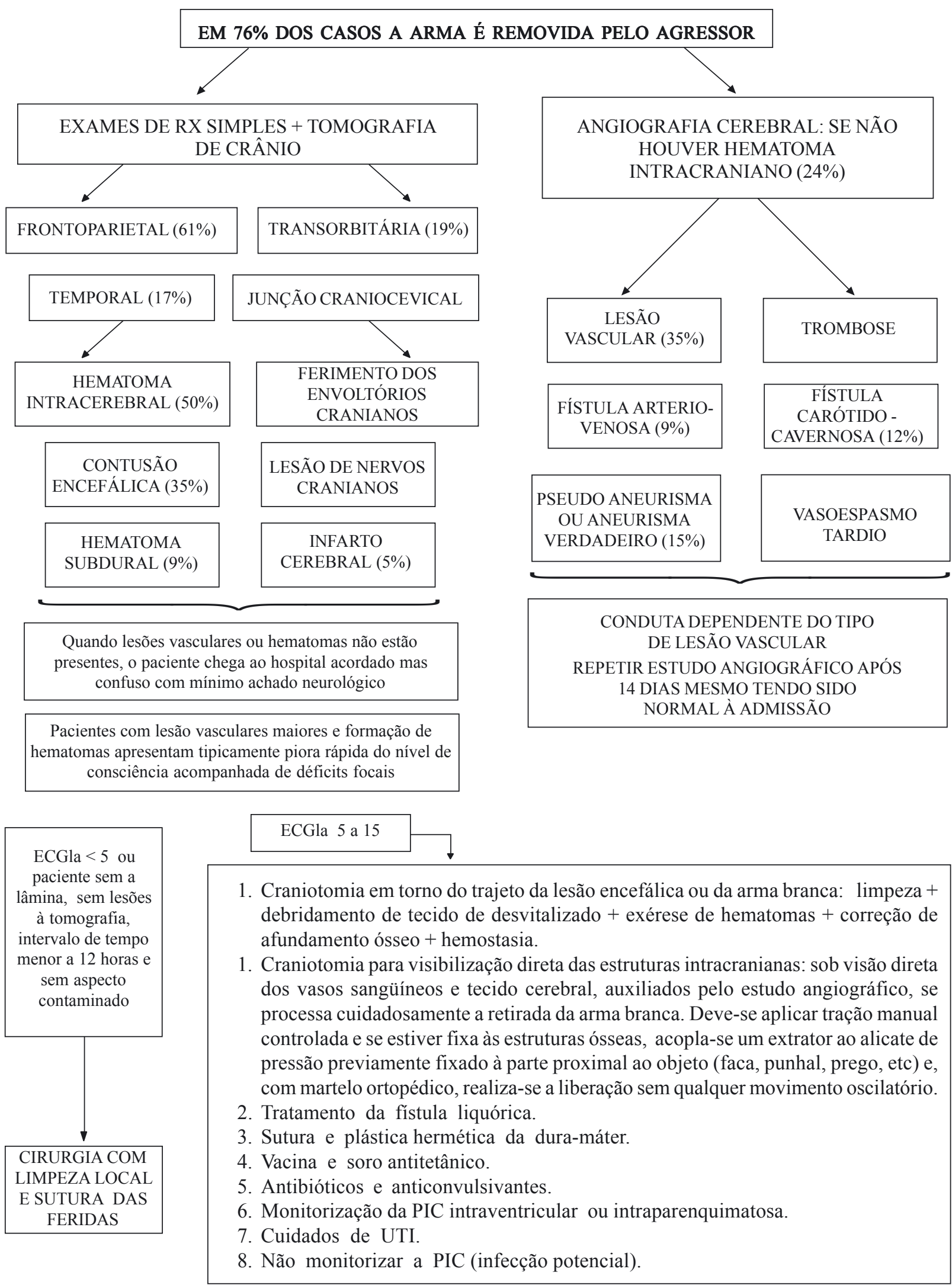




\section{CLASSIFICAÇÃO DAS FÍSTULAS DE LCR}

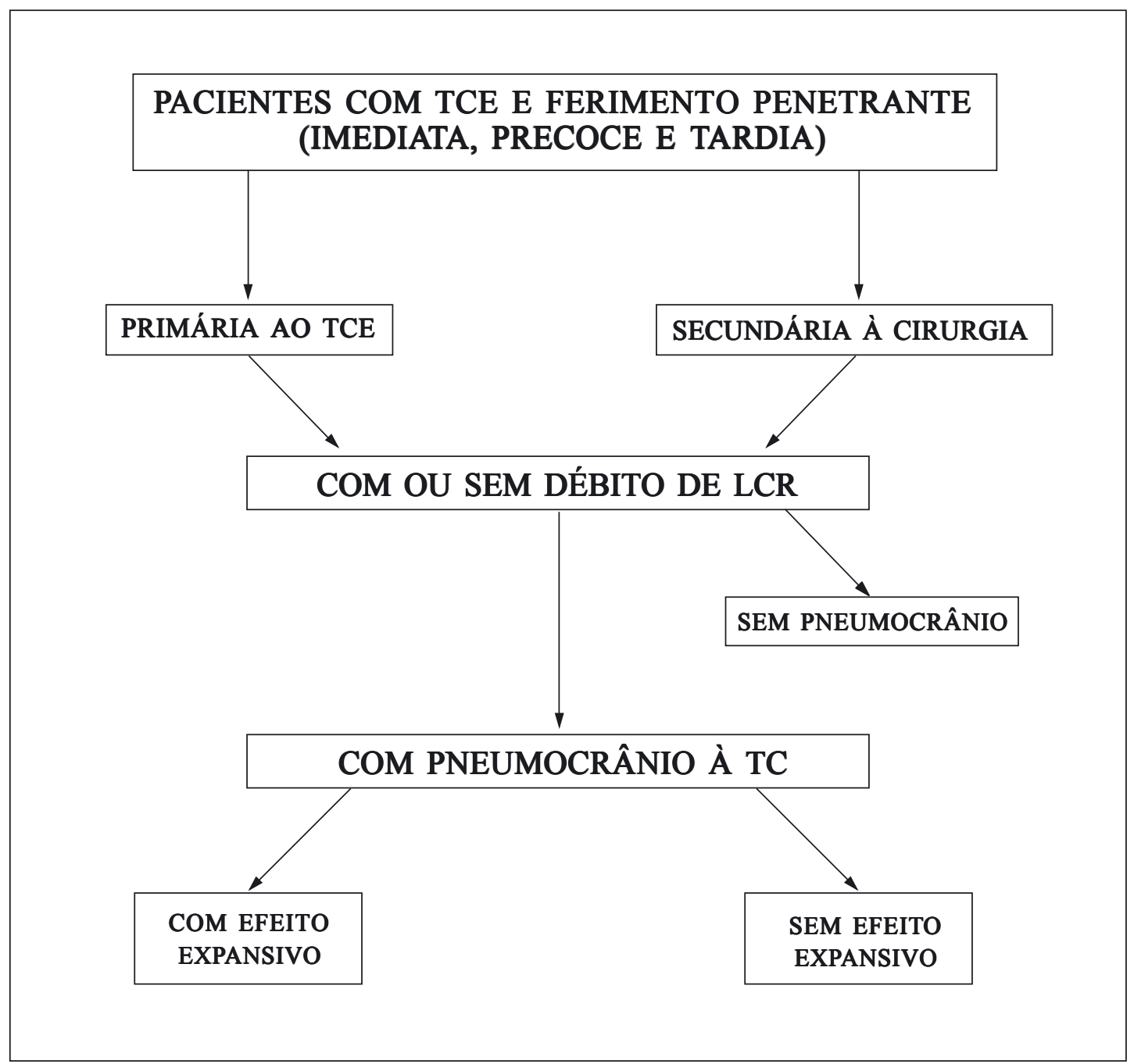




\section{FÍSTULA LIQUÓRICA PÓS-TRAUMÁTICA}

\section{Medidas clínicas}

1. Repouso em decúbito dorsal horizontal com elevação da cabeceira do leito a 30 graus.

2. Coletor plástico para controle do débito liquórico.

3. Antibioticoterapia adotada no serviço.

4. Hidratação durante as medidas clínicas.

5. Rinoscopia endoscópica diagnóstica e/ou otoscopia.

6. Oclusão ocular noturna + pomada e colírio oftálmicos na paralisia facial periférica.

7. Observação por dois dias. Se houver remissão do débito, observar por mais três dias antes da alta.

8. Fístula sem débito com pneumocrânio na TC: acompanhar com punções e análises do LCR.

\section{Tratamento cirúrgico-drenagem liquórica}

1. Punção lombar de repetição com múltiplas perfurações durais (se a TC não for sugestiva de HIC) por três ou cinco dias, com coleta de $20 \mathrm{ml}$ de LCR, no máximo. Se houver remissão em três dias, manter o paciente em observação por mais dois antes da alta.

2. Derivação lombar externa (DLE) com válvula por três dias.

3. Quando ocorrer recidiva após DLE, a derivação lomboperitoneal com cateter de James, Spetzler ou similar.

4. Tratamento endoscópico otorrinolaringológico.

5. Craniotomia uni ou bilateral para correção direta intra ou extradural.

\section{Pneumocrânio hipertensivo}

1. Oxigenação com $\mathrm{FiO}_{2}$ a $100 \%$.

2. Oxigenação hiperbárica.

3. Punção da bolha gasosa por trepanação craniana. 


\section{CONDUTA NA FÍSTULA LIQUÓRICA PÓS-TRAUMÁTICA AGUDA}

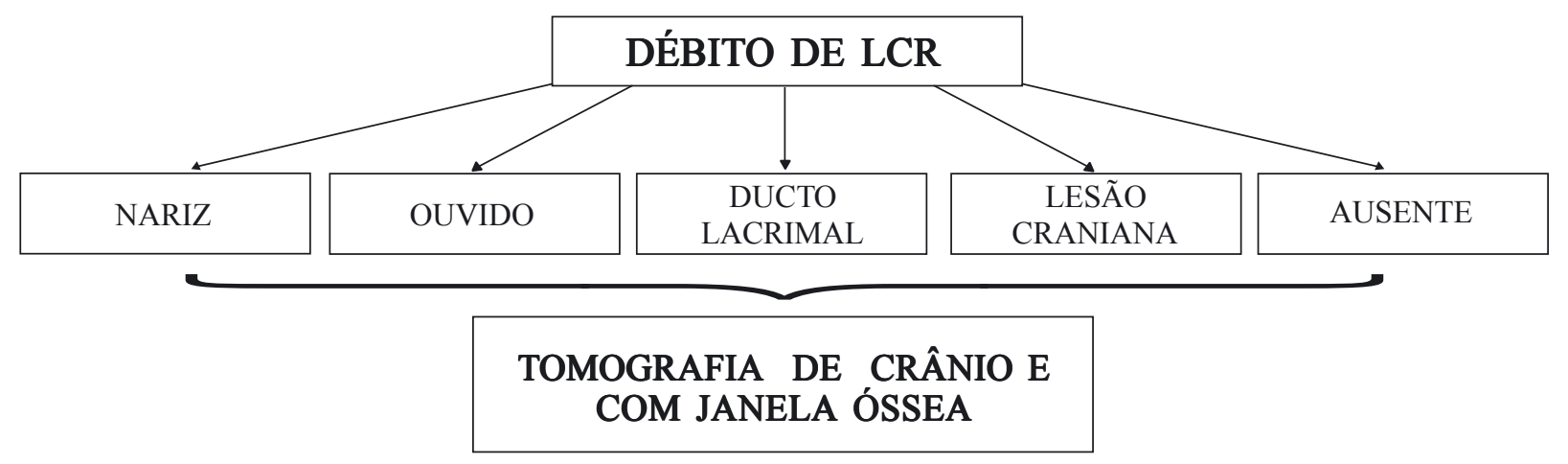

\begin{tabular}{|l|}
\hline AFUNDAMENTO \\
DA REGIÃO \\
TEMPORAL COM \\
FRATURA \\
TRANSVERSA OU \\
LONGITUDINAL \\
DO ROCHEDO: \\
PESQUISAR \\
LESÃO DE VII E VIII \\
NERVOS \\
\hline
\end{tabular}

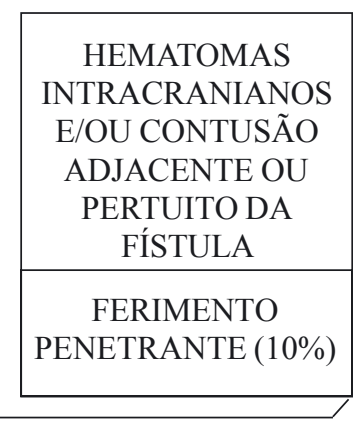

AFUNDAMENTO

FRONTO-ÓRBITO

BASAL E DOS SEIOS

CRANIOFACIAIS:

PESQUISAR LESÃO

DE I, II, III, IV, V

E VI NERVOS

\section{T. \\ CRANIOTOMIA COM ABORDA- GEM DIRETA DA FÍSTULA EX- TRA E INTRADURAL COM PLÁSTICA DE DURA-MÁTER E DE APONEUROSE PEDICULADA SUTURADA EM PONTOS SEPA- RADOS DA DURA-MÁTER}

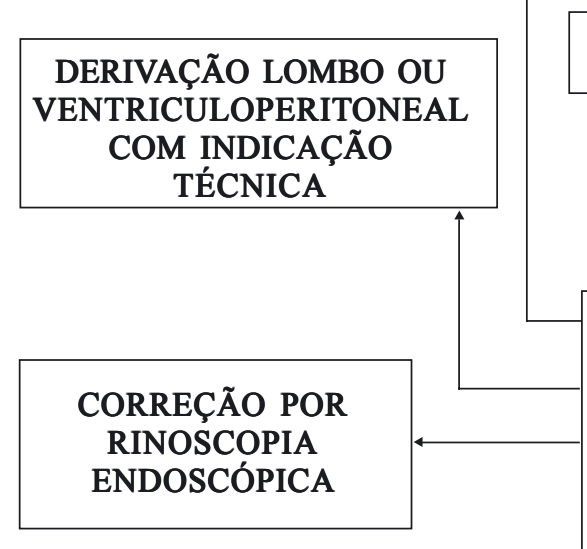

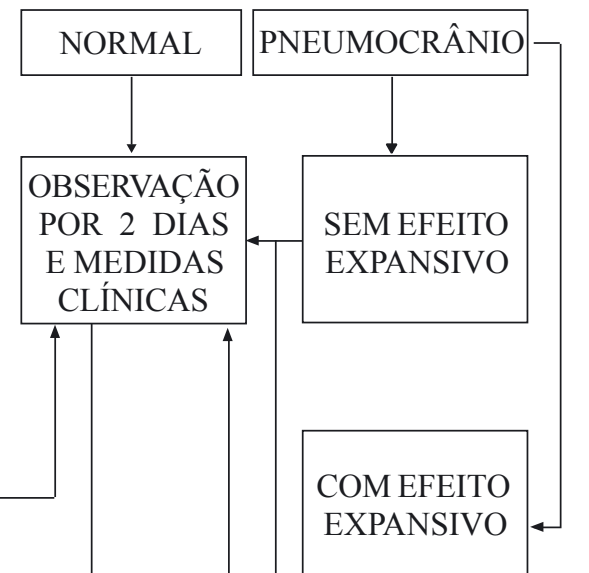

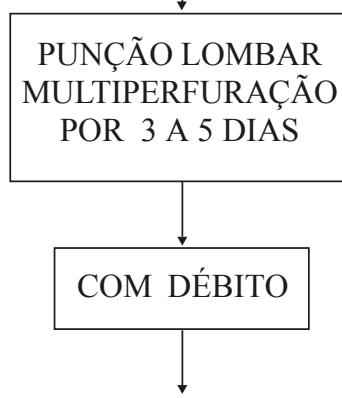

DLE POR 3 A 5 DIAS

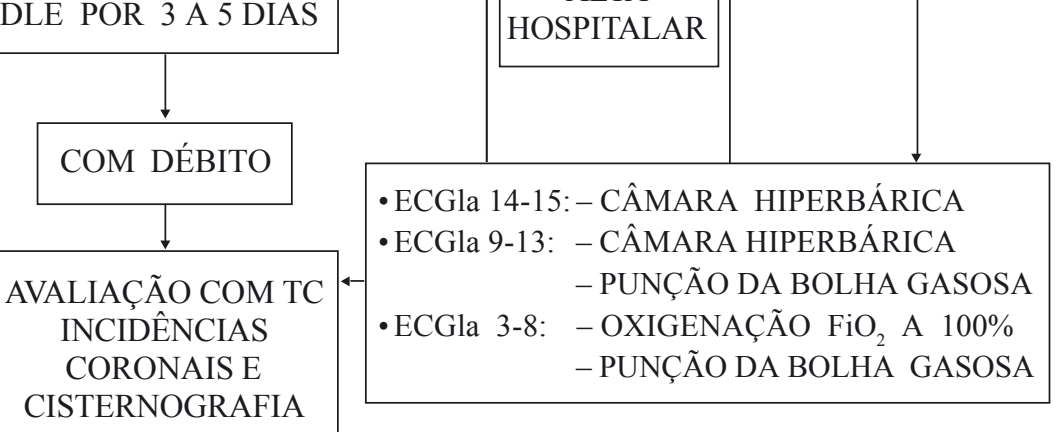

CISTERNOGRAFIA

OU CISTERNO

CINTILOGRAFIA

LOMBAR Tc-DTPA 


\section{ESPANCAMENTO INFANTIL}

\section{CAUSA DE $10 \%$ DOS TRAUMAS EM MENORES DE 5 ANOS}

CRIANÇA ESPANCADA

(Síndrome de Kemp)

menores de 3 anos

\begin{tabular}{|c|}
\hline "SHAKEN-BABY" \\
(Síndrome de Caffey) \\
menores de 2 anos, principalmente \\
abaixo dos 6 meses de idade \\
\hline
\end{tabular}

CRIANÇA NEGLIGENCIADA

muito freqüente

\section{HISTÓRIA}

- QUEDAS FREQÜENTES; TCE GRAVE POR TRAUMATISMO LEVE; ADMISSÕES FREQÜENTES POR TCE OU POLITRAUMATISMOS; VÁRIOS MECANISMOS ACIDENTAIS; MÚLTIPLAS LESÕES.

- SEM HIGIENE, MAL CUIDADA, SEM EDUCAÇÃO, GROSSEIRA, DISTÚRBIO DE COMPORTAMENTO E ALTERAÇÃO DE HUMOR.

- CRIANÇAS COM RELACIONAMENTO FAMILIAR PROBLEMÁTICO; PAIS ALCOÓLATRAS OU TOXICOMANÍACOS OU COM DISTÚRBIOS PSIQUIÁTRICOS.

- A AUSÊNCIA DESSAS INFORMAÇÕES NÃO AFASTAM A SUSPEITA DE CRIANÇA ESPANCADA.

- PROCURA DE ATENDIMENTO MÉDICO PELOS PAIS OU PARENTES TARDIAMENTE APÓS O ACIDENTE.

EXAME DE RAIOS X
- FRATURA DE OSSOS LONGOS (PRINCIPAL-
MENTE QUANDO MÚLTIPLA).
- FRATURA CRANIANA (PRINCIPALMENTE NA
ESCAMA DO OCCIPITAL).
TOMOGRAFIA
- HEMATOMA SUBDURAL AGUDO, PRINCIPALMEN
TE QUANDO INTER-HEMISFÉRICO POSTERIOR.
- HEMATOMA SUBDURAL CRÔNICO, EXTRADU-
RAL, INTRAPARENQUIMATOSO OU SINAIS DE
LESÃO AXONAL DIFUSA.
"BLACK BRAIN": LESÃO HIPOATENUANTE
CÓRTICO-SUBCORTICAL SEMELHANTE AÓ
INFARTO (DESMIELINIZAÇÃO PÓS-TRAUMÁ-
TICA SECUNDÁRIA).
- ATROFIA CEREBRAL DIFUSA.

EXAMES FÍSICO E NEUROLÓGICO

- MÚlTIPLAS LESÕES NA PELE POR DIVERSOS AGENTES; HEMATOMAS DO COURO CABELUDO, CÉFALO-HEMATOMAS; EQUIMOSE PALPEBRAL OU RETROAURICULAR, PRINCIPALMENTE NÃORELACIONADOS AO ACIDENTE.

- SINAIS DE TRAUMATISMOS ANTIGOS.

- FUNDO DE OLHO: HEMORRAGIA DE RETINA OU EDEMA DE PAPILA.

- RETARDO PSICOMOTOR OU SINAIS NEUROLÓGICOS DE LOCALIZAÇÃO.

- CRIANÇA COM DIMINUIÇÃO DO NÍVEL DE CONSCIÊNCIA SEM SINAIS FÍSICOS CERVICO. CRANIANOS APARENTES, COM DIAGNÓSTICO DE ENCEFALOPATIA HIPÓXICA; SUSPEITA DE SUFOCAMENTO.

\section{CONDUTA}

- APROPRIADA AO TIPO DE LESÃO.

- CONSULTA NEUROPSICOLÓGICA E PSIQUIÁTRICA.

- ACIONAR O SERVIÇO SOCIAL E O JUIZADO DE MENORES.

\section{OBSERVAÇÕES}

- MAIS DE 50\% COM EVIDÊNCIAS DE TCE.

- MORTALIDADE DE $10 \%$ A $27 \%$.

- DANOS NEUROLÓGICOS SEVEROS EM 25\%. 


\section{TRAUMATISMOS CRANIOENCEFÁLICOS OBSTÉTRICOS}

\begin{tabular}{|l|}
\hline Céfalo-hematoma \\
- DOIS POR CENTO DOS PARTOS \\
(MAIS FREQÜENTE EM PREMA- \\
TUROS). \\
- HEMORRAGIA SUBPERIOSTAL \\
LIMITADA À SUTURA. GERAL- \\
MENTE PARIETAL UNILATERAL. \\
- ASSOCIADO COM FRATURAEM \\
25\%. \\
- BOM PROGNÓSTICO E RESO- \\
LUÇÃO ESPONTÂNEA.
\end{tabular}

\begin{tabular}{|c|}
\hline $\begin{array}{l}\text { Hemorragia } \\
\text { subaracnóidea } \\
\text { • GERALMENTE DEVIDO A CANAL } \\
\text { DE PARTO ESTREITO. } \\
\text { • RELACIONADO À PREMATU- } \\
\text { RIDADE, DISTOCIA, APRESEN- } \\
\text { TAÇÃO PÉLVICAE/OU TRABALHO } \\
\text { DE PARTO PROLONGADO. } \\
\text { - PRATICAMENTE SEM SINAIS } \\
\text { CLÍNICOS. } \\
\text { - PODE EVOLUIR COM QUADRO } \\
\text { DE HIDROCEFALIA. }\end{array}$ \\
\hline
\end{tabular}

\begin{tabular}{|c|}
\hline Fraturas cranianas \\
• CAUSADAS POR COMPRESSÃO \\
DO FÓRCEPS OU PRESSÃO CON- \\
TRA O PROMONTÓRIO MA- \\
TERNO. \\
• LINEARES E AFUNDAMENTO \\
EM BOLA DE PINGUE-PONGUE. \\
- APRESENTA SINAIS EXTERNOS \\
DE TRAUMA. \\
RARAMENTE HÁ LESÕES DE \\
DURA-MÁTER.
\end{tabular}

\begin{tabular}{|c|}
\hline Hematoma \\
subdural agudo \\
• LESÃO FREQÜENTE E GRAVE. \\
- CAUSADO POR COMPRESSÃO \\
HORIZONTAL DO CRÂNIO. \\
- O SANGRAMENTO PODE OCOR- \\
RER DESDE A BASE DE CRÂNIO \\
ATÉ A REGIÃO INTER-HEMIS- \\
FÉRICA. QUADRO CLÍNICO COM \\
CONVULSÕES, FONTANELATEN- \\
SA, ALTERAÇÕES RESPIRATÓ- \\
RIAS E DÉFICIT FOCAL. \\
•TRATAMENTO EMINENTEMENTE \\
CIRÚRGICO.
\end{tabular}

\begin{tabular}{|l|}
\multicolumn{2}{c|}{ Hematoma } \\
extradural agudo \\
- RARO. \\
- ASSOCIADO COM O USO DE \\
FÓRCEPS. \\
- QUADRO CLÍNICO DE PALIDEZ \\
CUTÂNEA, DÉFICIT FOCAL E \\
FONTANELA TENSA. \\
- TRATAMENTO EMINENTEMEN- \\
TE CIRÚRGICO. \\
\end{tabular}

\begin{tabular}{|c|}
\hline Hematoma \\
intracerebral \\
• PODE OCORRER ATÉ 24 HORAS \\
APÓS O TRAUMA. \\
- GERALMENTE TEMPORAL, PO- \\
DENDO ESTAR, ASSOCIADO COM \\
DISCRASIAS SANGÜÍNEAS. \\
- QUADRO CLÍNICO COM CON- \\
VULSÕES FOCAIS OU GENERA- \\
LIZADAS. \\
- TRATAMENTO CIRÚRGICO QUAN- \\
DO INDICADO. \\
\end{tabular}




\section{PACIENTES COM TCE E/OU POLITRAUMATISMO E ALTERAÇÃO NEUROLÓGICA COM TOMOGRAFIA NORMAL}
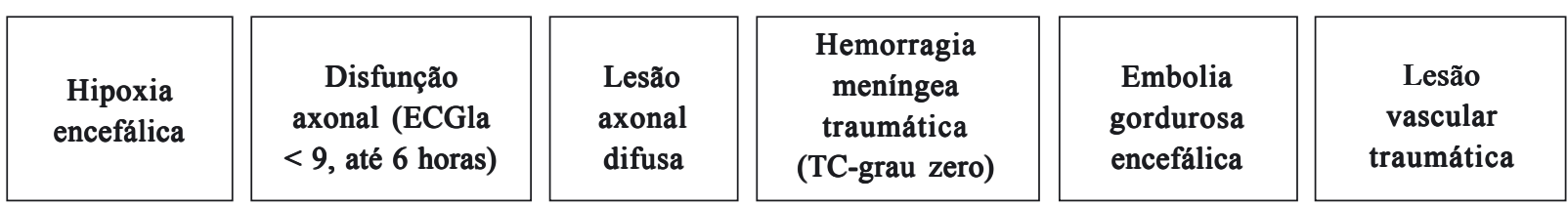

\begin{tabular}{|l|}
\hline RM: normal. \\
Oximetria \\
digital: hipoxia \\
ou gasometria \\
com $\mathrm{PaO}_{2} \leq 60$ \\
$\mathrm{mmHg}$ ou \\
ocorrência de \\
apnéia ou \\
cianose. \\
Hipotensão: \\
PAS $\leq 90$ mmHg \\
(em $34,6 \%$ ). \\
Associada a $85 \%$ \\
de aumento da \\
mortalidade. \\
Hipoxia hipóxica \\
(em 30\%). \\
Hipoxia.
\end{tabular}

RM: normal (convencional).

Espectroscopia por RM: distúrbio iônico

e do glutamato.

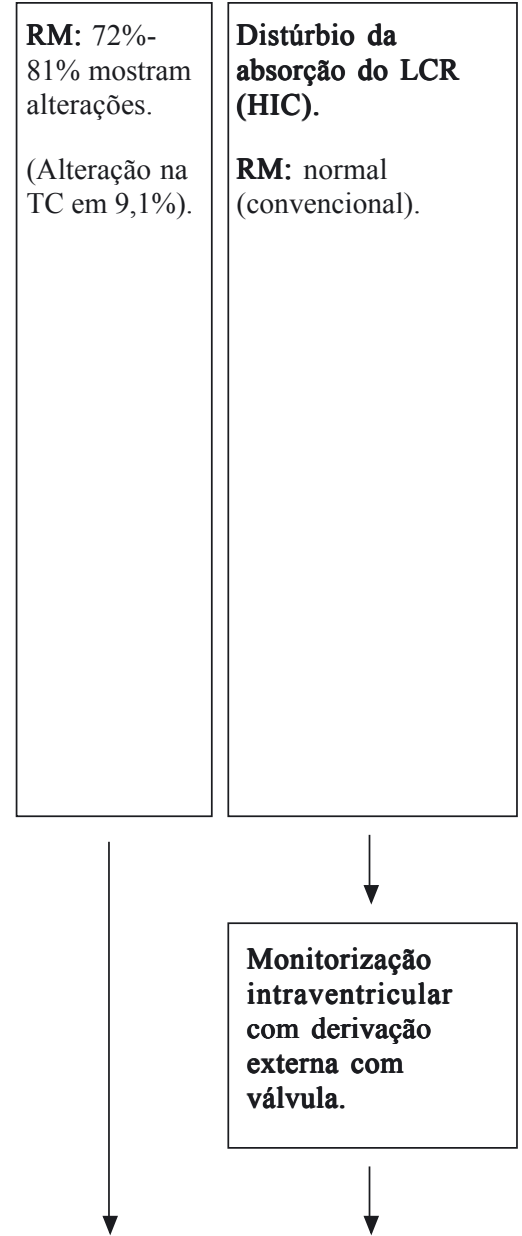

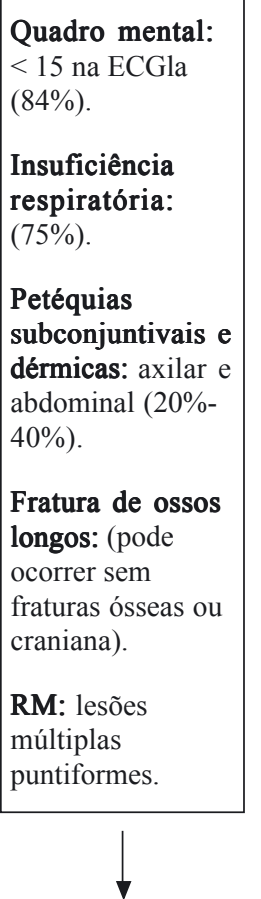

\section{Trombose} Traumática de artéria carótida interna: paciente com ECGla $=15$, com hemiplegia ou afasia.

Fístula carótidocavernosa: cefaléia, proptose, quemose, oftalmoplegia e diminuição de acuidade visual.

TC contrastada, angiografia e/ou RM: diagnóstico.

Dexametasona

(4 mg) ou solumedrol (250 $\mathrm{mg}) \mathrm{EV}$ de $6 \mathrm{em}$ 6 horas.
Procedimento endovascular (preservação do $90 \%$ ). lúmen arterial em

\section{Suporte básico em UTI com monitorização contínua da PIC e temperatura} cerebral + hipotermia leve 


\section{DIRETRIZES BÁSICAS PARA O TRATAMENTO DE HIPERTENSÃO INTRACRANIANA}

1. Indicada quando a PIC $>15 \mathrm{mmHg}$ em situações como a de lesão expansiva nos lobos temporal ou frontal; PIC > $20 \mathrm{mmHg}$ por mais de 5 minutos ou com ondas patológicas (A e B) com grande amplitude.

2. Manter a pressão de perfusão cerebral (PPC) normal, ou seja, entre $80 \mathrm{mmHg}$ e $150 \mathrm{mmHg}$.

3. Elevação do dorso do leito a $30^{\circ}$ e evitar flexões, extensões e movimentos laterais cervicocranianos além de $15^{\circ}$, mantendo-se o alinhamento neutro.

4. Manter vias aéreas pérvias e ventiladas.

5. Durante a fisioterapia, as aspirações e os banhos, controlar os níveis de PIC; não manter a PIC elevada por mais de 5 minutos intermitentemente.

6. Verificar o funcionamento do sistema de monitorização da PIC pelas manobras (tosse, aspiração, compressão, veias jugulares por 10 segundos). Anotar a elevação da PIC por artefatos.

7. Determinação da complacência intracraniana:

a. compressão das jugulares internas por 10 segundos (normal = elevação e queda rápida da PIC);

b. ondas patológicas "B" e "A" de grande amplitude;

c. teste de relação volume/pressão (somente em pacientes com níveis de PIC normais): infusão de $0,1 \mathrm{ml}$ no sistema, a cada três horas, (normal = elevação até $5 \mathrm{mmHg}$ ), diminuída até $20 \mathrm{mmHg}$ e exaustão $>20 \mathrm{mmHg}$ mantido.

8. Hiperventilação leve controlada em situações de hiperemia mantendo a $\mathrm{PCO}_{2}$ entre $30 \mathrm{mmHg}-35 \mathrm{mmHg}$.

9. Em situações de vasoespasmo ou situações de oligoemia, não realizar hiperventilação.

10. Hiperventilação leve e manitol a $20 \%$ em situações de herniação cerebral $(300 \mathrm{mg} / \mathrm{kg} / \mathrm{dose}$ de 4 em 4 horas para adultos e $150 \mathrm{mg} / \mathrm{kg} /$ dose de $4 \mathrm{em} 4$ horas para crianças). Osmalaridade sérica não deve aumentar acima de $320 \mathrm{mOsm}$.

11. Diminuir a viscosidade sangüínea com manitol $20 \%$ a cada 6 horas e hemodiluição $(\mathrm{Ht}=33-35)$.

12. Diagnosticar por doppler transcraniano e tratar alterações hemodinâmicas cerebrais: hiperemia, oliguemia e vasoespasmo.

13. Em UTIs que preconizam o tratamento por monitorização hemometabólica, diagnosticar e normalizar mantendo entre $24 \%$ a $42 \%$, estados de hiperemia ou oliguemia.

14. Suporte ventilatório, cardíaco, renal e hidroeletrolítico. 


\section{METODOLOGIA PARA PROTEÇÃO CEREBRAL COM MONITORIZAÇÃO CONTÍNUA DE PIC, TEMPERATURA CEREBRAL E ELETROENCEFALOGRAFIA}

1. Dose de ataque: midazolam de 7,5 mg a $15 \mathrm{mg}$ em infusão venosa (1 min-2 min); fentanil $3 \mathrm{mg} / \mathrm{kg}$.

2. Dose de manutenção: sedação com midazolam associado com fentanil na seguinte solução: SG 5\% 200 $\mathrm{ml}$, midazolan $75 \mathrm{mg}$ e fentanil $50 \mathrm{ml}$ (2,5 mg), ministrada na velocidade de $5 \mathrm{ml} / \mathrm{h}-15 \mathrm{ml} / \mathrm{h}$, devendo ser ajustada com base no nível de consciência. O fentanil deve ser dimuído ou suspenso se o paciente apresentar bradicardia relacionada e o midazolam deve ser suspenso se ocorrer hipotensão arterial sistêmica. (Apresentações: fentanil - frascos de $10 \mathrm{ml} \mathrm{com} 0,05 \mathrm{mg} / \mathrm{ml}$ e dormonid - ampolas de $3 \mathrm{ml}$ com $5 \mathrm{mg} / \mathrm{ml})$.

3. Coma barbitúrico induzido: (infusão IV de tiopental utilizando bomba de infusão na dose de $10 \mathrm{mg} / \mathrm{kg}$ durante $30 \mathrm{~min}+5 \mathrm{mg} / \mathrm{kg} / \mathrm{h}$ por 3 horas + manutenção com $1 \mathrm{mg} / \mathrm{kg} / \mathrm{hora} \mathrm{a} 3 \mathrm{mg} / \mathrm{kg} / \mathrm{hora}$ ). Ajustado pelo registro de EEG até o aparecimento de burst supression (ondas de supressão). O EEG não pode apresentar isoeletricidade durante a infusão. Na ausência do padrão de ondas de supressão durante os primeiros 30 min de indução, utiliza-se 200 mg IV em bolus).

4. Bloqueadores neuromusculares: brometo de pancurônio, ou brometo de vecurônio, se ocorrer taquicardia pelo uso do pancurônio. Doses excessivas devem ser evitadas, pois podem prolongar o período de desmame respiratório além de suprimir o sistema imunológico.

5. Hipotermia leve: (entre $34{ }^{\circ} \mathrm{C} \pm 0,3{ }^{\circ} \mathrm{C}$ ) ou hiportermia moderada (entre $32{ }^{\circ} \mathrm{C}$ e $33{ }^{\circ} \mathrm{C}+0,3{ }^{\circ} \mathrm{C}$ ), de acordo com o protocolo do serviço em anexo.

6. Anticonvulsivantes: fenitoína (infusão IV de $10 \mathrm{mg} / \mathrm{kg}$ a $20 \mathrm{mg} / \mathrm{kg}$ e manutenção de $300 \mathrm{mg} / \mathrm{dia}$ em três doses, no adulto).

\section{CONDUTAS CIRÚRGICAS PARA CONTROLE DA PIC REFRATÁRIA AO TRATAMENTO CLÍNICO}

1. Monitorização contínua da PIC intraparenquimatosa com ou sem monitorização concomitante da temperatura cerebral.

2. Monitorização contínua da PIC intraventricular com ou sem monitorização da temperatura cerebral.

3. Monitorização da PIC com drenagem contínua de LCR, pelo cateter intraventricular conectado por válvula ao sistema de derivação ventricular externa do monitor.

4. Craniotomia descompressiva com duroplastia na presença de tumefação cerebral hemisférica isolada ou associada com hematomas subdural ou extradural ou em lesões por infarto.

5. Craniotomia descompressiva e duroplastia com retirada do tecido desvitalizado em lesões hemorrágicas, ou laceração lobar.

6. Lobectomia temporal ou frontal do hemisfério não-dominante, nas contusões ou lacerações cerebrais.

7. Lobectomia temporal ou frontal do hemisfério dominante, apenas em tecido cerebral desvitalizado.

8. Não utilizar lobectomias ou amígdalo-hipocampectomia como métodos descompressivos em tecidos sadios. 


\section{PROTOCOLO DE PROTEÇÃO CEREBRAL POR HIPOTERMIA EM PACIENTES COM TCE GRAVE}

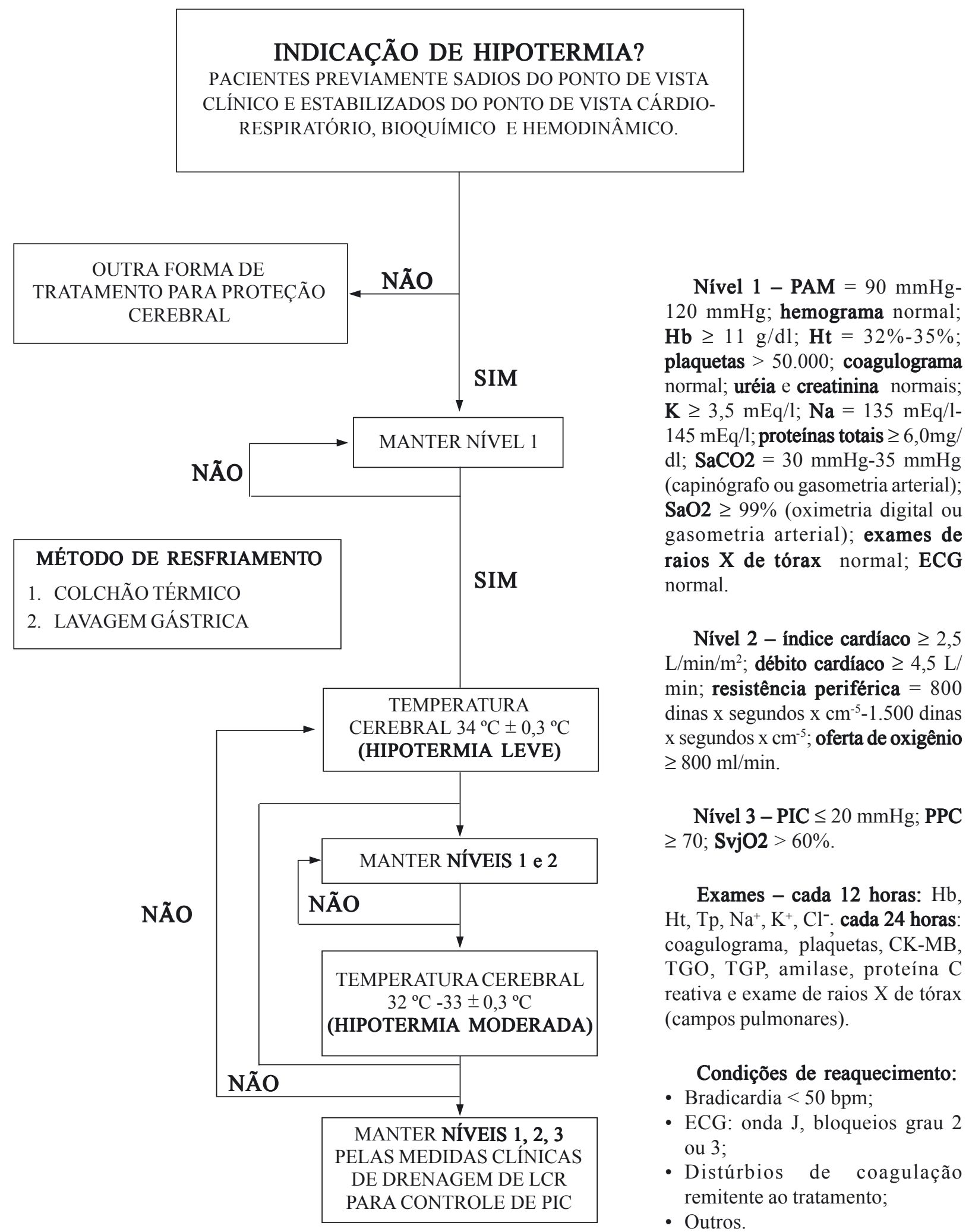




\section{PROTOCOLO DE DIAGNÓSTICO E TRATAMENTO DA PIC E DA TEMPERATURA CEREBRAL NO TCE}

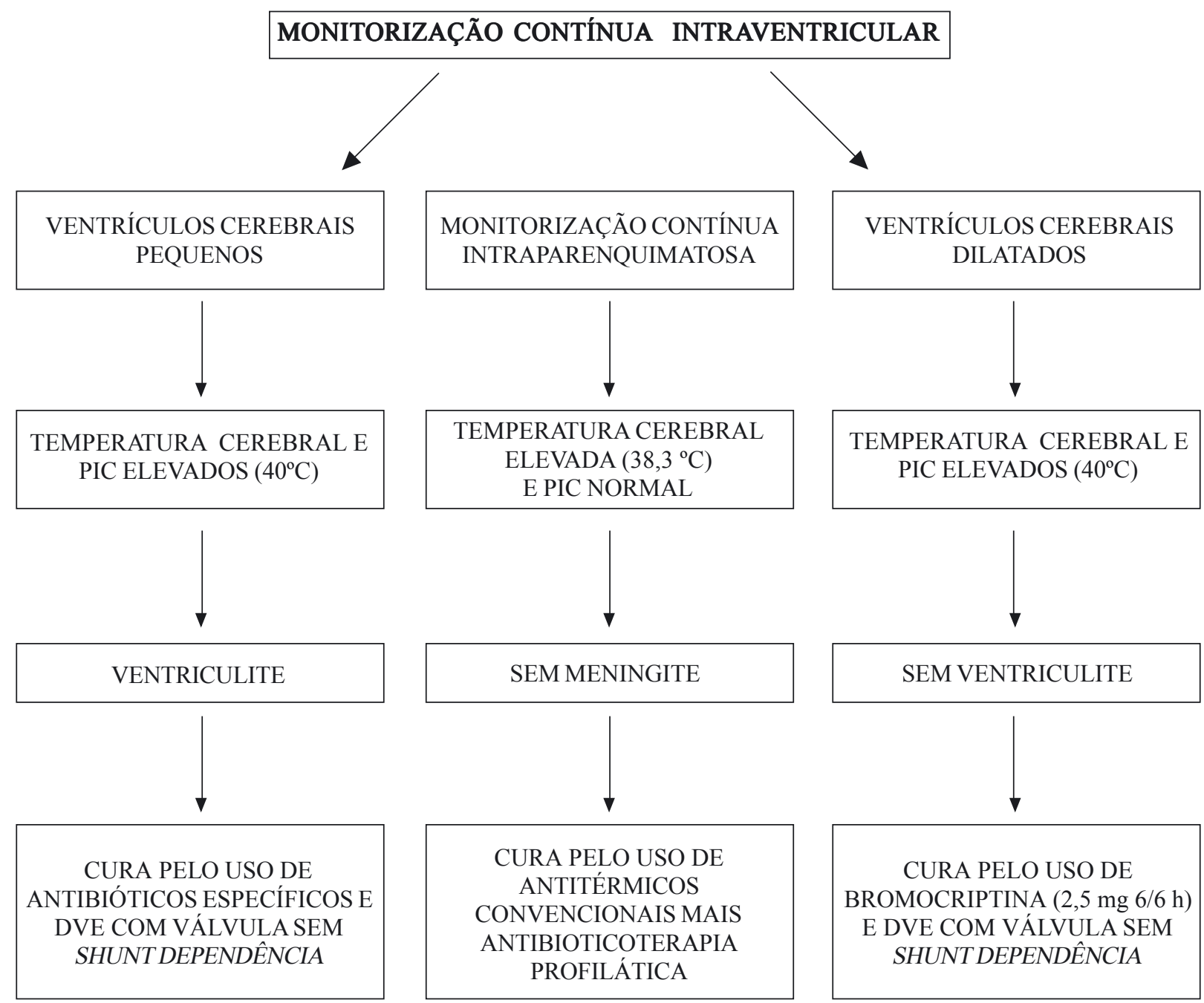

Temperaturas corporais de $38{ }^{\circ} \mathrm{C}-42{ }^{\circ} \mathrm{C}$ determinam o aumento do metabolismo cerebral; acima de $42{ }^{\circ} \mathrm{C}$ ocorre hipometabolismo cerebral difuso determinando ondas cerebrais lentas ao EEG. 


\section{MONITORIZAÇÃO HEMOMETABÓLICA}

\section{Monitorização hemometabólica intermitente}

EXTRAÇÃO CEREBRAL DE OXIGÊNIO $\left(\mathrm{ECO}_{2}=\mathrm{SaO}_{2}-\mathrm{SvjO}_{2}\right)$

Valores normais para normovolemia: $\mathrm{ECO}_{2}=24 \%-42 \%$; $\mathrm{PaCO}_{2}=35 \mathrm{mmHg}-45 \mathrm{mmHg}$; $\mathrm{Hb}>10 \mathrm{~g} / \mathrm{dl} ; \mathrm{SaO}_{2}>95 \% ;$ PAM $=90 \mathrm{mmHg} ;$ PPC $>70 \mathrm{mmHg}$.

\section{DIRETRIZES BÁSICAS}

PIC $>20 \mathrm{mmHg}$ e $\mathrm{ECO}_{2}$ medida $>42 \% \rightarrow$ manitol até que a $\mathrm{ECO}_{2}$ se normalise (hipoxia oligoêmica). PIC $>20 \mathrm{mmHg}$ e $\mathrm{ECO}_{2}$ medida $=32 \%-42 \% \rightarrow$ manitol e barbitúrico se necessário.

$\mathrm{PIC}>20 \mathrm{mmHg}$ e $\mathrm{ECO}_{2}$ medida $<24 \%$ (hiperemia cerebral)* $\rightarrow$ hiperventilação $\left(\mathrm{PaCO}_{2} \sim 25\right.$ $\mathrm{mmHg}$ ).

PIC $>20 \mathrm{mmHg}$ e $\mathrm{ECO}_{2}$ medida $>\mathbf{4 2} \%$ (hipoxia oligoêmica) $\rightarrow$ manitol até que a $\mathrm{ECO}_{2}$ se normalize. $\mathrm{PIC}>20 \mathrm{mmHg}$ e ECO 2 medida $=24 \%-32 \% \rightarrow$ hiperventilação moderada $\left(\mathrm{PaCO}_{2}=25-30 \mathrm{mmHg}\right)$. $\mathrm{PIC}<20 \mathrm{mmHg}$ (normal) e $\mathrm{ECO}_{2}$ medida $<24 \% \rightarrow$ não hiperventilar ou hiperventilação discreta $\left(\mathrm{PaCO}_{2}=30 \mathrm{mmHg}-35 \mathrm{mmHg}\right)$ (hiperemia cerebral).

$\mathrm{PIC}<20 \mathrm{mmHg}$ (normal) e $\mathrm{ECO}_{2}$ medida $>42 \% \rightarrow$ aumentar a $\mathrm{PaCO}_{2}$ em até $5 \mathrm{mmHg}-7 \mathrm{mmHg}$ de cada vez.

* Com hipertensão intracraniana mais acentuada, combinar, precocemente, hiperventilação otimizada, manitol, barbitúrico e manter $\mathrm{ECO}_{2}$ normal. Interromper manitol quando a osmolalidade plasmática $>315 \mathrm{mOsm} / 1$ (exceto em episódios de herniação tentorial - repetir TC). 


\section{MONITORIZAÇÃO HEMOMETABÓLICA}

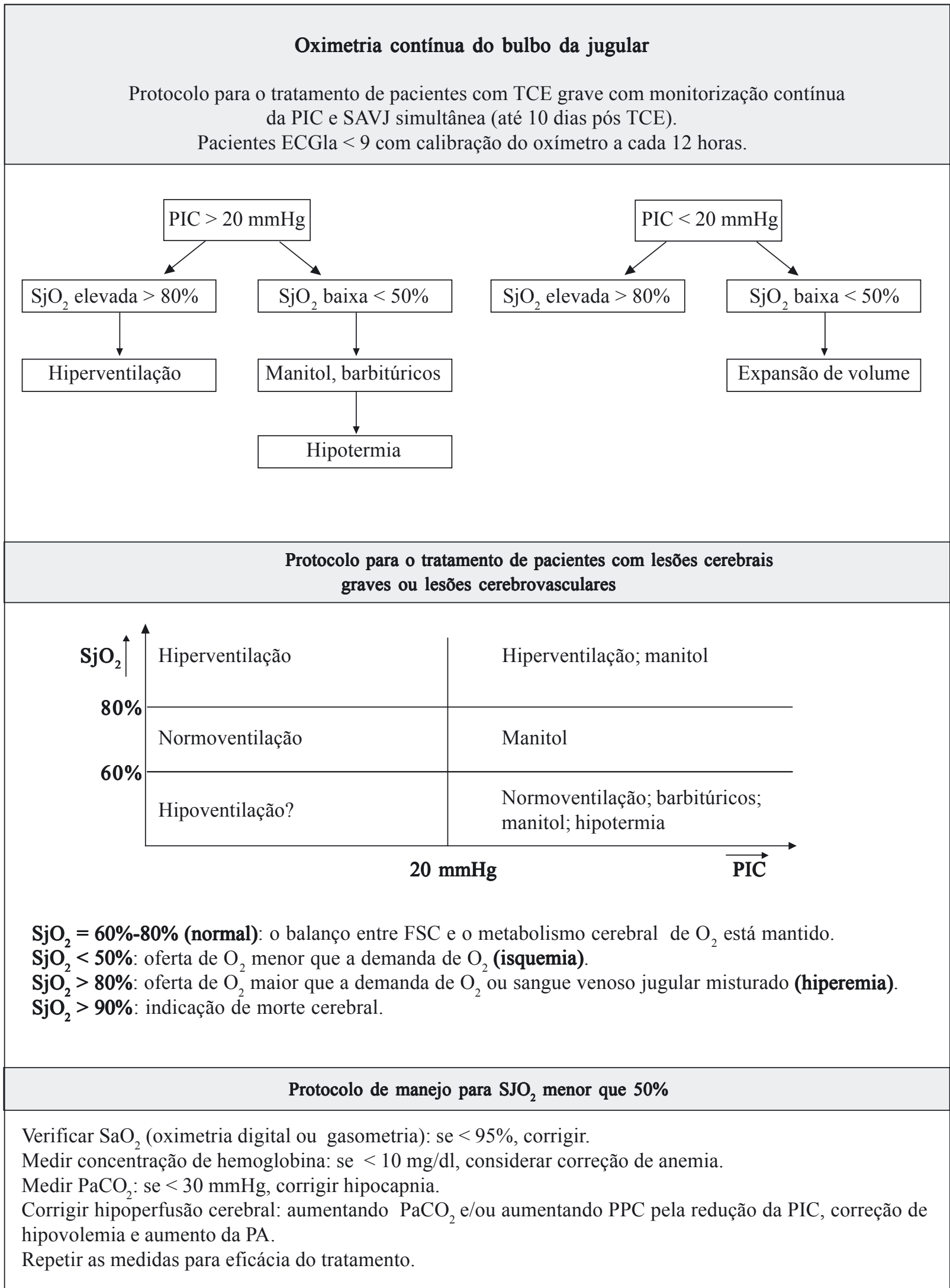




\title{
ESCALA DE EVOLUÇÃO DE GLASGOW
}

- Recuperação completa: Retorno ao trabalho e à atividade social sem déficits neurológicos $=5$.

- Inabilidade leve - moderada: Trabalho limitado, necessitando ajuda para realizar tarefas $=4$.

- Inabilidade grave: Incapaz de realizar trabalho, requerendo ajuda para atividades cotidianas $=3$.

- Estado vegetativo persistente $=2$.

- Morte $=1$.

\section{CRITÉRIOS DIAGNÓSTICOS DE MORTE ENCEFÁLICA CONSELHO FEDERAL DE MEDICINA}

\author{
Critérios de morte encefálica para pacientes acima de 2 anos de idade e adultos
}

\section{1 - Coma aperceptivo}

Ausência de reflexos ou movimentos supra-espinhais, excluindo-se hipovolemia, hipotensão, hipotermia ou uso de drogas depressoras do sistema nervoso central (barbitúricos, curare, diazepínicos). Nesses pacientes é importante aguardar o período necessário para eliminação dessas drogas, quando se pretende o diagnóstico de morte encefálica. O intervalo mínimo entre as duas avaliações clínicas a ser observado para constatação de morte encefálica nessa faixa etária é de 6 horas. O achado clínico deverá ser necessariamente respaldado por um exame complementar que demonstre, inequivocamente, a ausência de atividade elétrica cerebral, do tronco encefálico, ausência de perfusão sangüínea cerebral ou de atividade metabólica:

- pupilas paralíticas - as pupilas devem estar fixas e arreativas frente a um estímulo luminoso;

- arreatividade supra-espinhal;

- ausência do reflexo córneo-palpebral;

- ausência de reflexo vestíbulo-ocular: pesquisa pela movimentação lateral ou vertical da cabeça ou pela irrigação dos condutos auditivos com $50 \mathrm{ml}$ de água gelada;

- ausência do reflexo óculocefálico;

- ausência de reflexo nauseoso.

\section{2 - Prova da apnéia}

- ventilar com $\mathrm{FiO}_{2}$ de $100 \%$ durante período que estiver em CPAP;

- desconectar o ventilador do paciente;

- instalação de catéter traqueal de $\mathrm{O}_{2}$ com fluxo de $6 \mathrm{l} / \mathrm{min}$;

- observar, por 10 minutos, se há movimentos respiratórios; repetir gasometria arterial, cuja $\mathrm{PaCO}_{2}$ deve ser $\geq 55 \mathrm{mmHg}$. A cada minuto de apnéia, a $\mathrm{PaCO}_{2}$ aumenta de $3 \mathrm{mmHg}$, portanto, após 10 minutos, teremos uma ascensão da $\mathrm{PaCO}_{2}$ em $30 \mathrm{mmHg}$; obviamente, se houver algum movimento respiratório, o paciente não está em apnéia e, portanto, não há morte encefálica.

Obs.: se a $\mathrm{PaCO}_{2}$ inicial já estiver elevada (acima de $40 \mathrm{mmHg}$ ), está contra-indicado o teste de apnéia. A contra-indicação também se aplica aos pacientes cardiopatas descompensados.

\section{3 - Exames subsidiários}

- circulação cerebral: angiografia de artérias carótidas e vertebrais; doppler transcraniano e de artérias carótidas internas; angiografia isotópica com Tc99m DTPA ou Tc99m ECD;

- atividade elétrica cerebral: eletroencefalograma; potencial evocado;

- atividade metabólica cerebral: SPECT com Tc99m HMPAO ou Tc99m ECD; extração cerebral de oxigênio. 


\title{
CRITÉRIOS DIAGNÓSTICOS DE MORTE ENCEFÁLICA CONSELHO FEDERAL DE MEDICINA
}

\author{
Critérios de morte encefálica para crianças entre 7 dias e 2 anos incompletos de idade
}

\section{1 - História}

Determinar a causa (etiologia) do coma para eliminar condições de reversibilidade como hipotermia, hipotensão arterial sistêmica, drogas depressoras do sistema nervoso central, etc.

\section{2 - Exame neurológico}

- coma aperceptivo;

- ausência de reflexos ou movimentos supra-espinais;

- pupilas arreativas;

- ausência de reflexo óculo-cefálico, vestíbulo-ocular, corneopalpebral e nauseoso;

- apnéia;

- arreatividade motora, excluídos os reflexos medulares;

- exame alterado com período mínimo de tempo determinado de acordo com a idade:

- de 7 dias a 2 meses incompletos: dois EEGs isoelétricos com intervalo de $48 \mathrm{~h}$;

- de 2 meses a 1 ano incompleto: dois EEGs isoelétricos com intervalo de $24 \mathrm{~h}$;

- de 1 ano a 2 anos incompletos: dois EEGs isoelétricos com intervalo de $12 \mathrm{~h}$ ou qualquer outro exame complementar.

Obs.: o exame neurológico do recém-nascido é baseado fundamentalmente na avaliação do tronco cerebral. Nos prematuros, essa avaliação é problemática, pois parte desses reflexos estão ausentes normalmente (ausência do reflexo vestibular à estimulação calórica tanto pela exigüidade do conduto auditivo externo como pela ototoxicidade por hiperbilirrubinemia. Os exames subsidiários são igualmente problemáticos nos prematuros. Assim, o EEG isoelétrico pode voltar a demonstrar atividade, bem como resíduos de FSC podem retornar. 


\section{Bibliografia Recomendada}

ANDRADE AF: Medida contínua da pressão intracraniana extradural para avaliação do traumatismo cranioencefálico. Tese (mestrado) apresentada à Faculdade de Medicina da Universidade de São Paulo, 1982.

ANDRADE AF: Medida contínua da pressão intracraniana subdural para avaliação do traumatismo cranioencefálico. Tese (doutorado) apresentada à Faculdade de Medicina da Universidade de São Paulo, 1990.

ASLID R, NEWELL DW: Head injury and cerebral circulatory arrest. In: Newell DW, Aaslid R (ed): Transcranial Doppler. NY Raven Press, 1992, pp109-121.

CARDOSO ER, ROWAN JO, GALBRAITH S: Analysis of the cerebrospinal fluid pulse wave in intracranial pressure. J Neurosurg 59:817-21, 1983.

CHAMPION HR, SACCO WJ, CARNAZZO AJ: Trauma score. Crit Care Med 9:672-6, 1981.

COOPER PR: Head Injury. Ed 3. Baltimore, 1993.

CZOSNYKA M, MATTA BF, SMIELEWSKI P, KIRKPATRIK $P, P I C K A R D J:$ Cerebral perfusion pressure in head-injured patients: a noninvasive assessment using transcranial Doppler ultrasonography. J Neurosurg 88:802-8, 1998.

HIRSCH R: A contribuição do doppler transcraniano para investigação do acidente vascular cerebral isquêmico. Tese (doutorado) apresentada à Faculdade de Medicina da Universidade de São Paulo, 1998

HSIANG JNK, YEUNG T, ASHLEY LM, POON WS: High risk mild head injury. J Neurosurg 78: 234-38, 1997.

LAMBERTUCCI JR: Febre. Diagnóstico e tratamento. MEDSI Editora Médica e Científica Ltda. Rio de Janeiro, 1991, pp 1-321.

LINDEGAARD KF, NORNES H, BAKKE SJ, SORTERBERG W, NAKSTAD P: Cerebral vasospasm diagnosis by means of angiography and blood velocity measurements. Acta Neurochir (Wien) 100:12-24, 1989. LUNDBERG N: Monitoring of the intracranial pressure. In: Crilchley M, O'Leary JL, jennet T (eds): Scientific foundation of neurology. F A Davis Company, Philadelphia, 1972, pp 356-71.
LUNDBERG N: Continuous recording and control of ventricular fluid pressure in neurosurgical practice. Acta Psychiat Neurol Scand 149:1-193, 1960.

MARION DW: Traumatic brain injury. New York, Thieme, 1999.

MARSHALL LF: The national traumatic como data bank. Part 2: patients who talk and deteriorate: implications for treatment. J Neurosurg 59:285-8,1983.

MASET A, ANDRADE AF, MARTUCCI SC, FREDERICO LM: Epidemiologic features of head injury in Brazil. Arq Bras Neurocir 12:293-302, 1993.

MELLERGARD P: Changes in human intracerebral temperature in response to different methods of brain cooling. Neurosurgery 31:671-677, 1992.

MELLERGARD P: Intracerebral temperature in neurosurgical patients: intracerebral temperature and relationships to consciousness level. Surg Neurol 43:9195, 1995.

MELLERGARD P, NORDSTROM CH, CHRISTENSSON M: A method for monitoring intracranial temperature in neurosurgical patients. Neurosurgery 27:654-657, 1990.

MILLER JD, BECKER DP, WARD JD, SULLIVAN HG, ADAMS WE, ROSNER MJ: Significance of intracranial hypertension in severe head injury. J Neurosurg 47: 50316, 1977.

NARAYAN RK: Neurotrauma. NY, McGraw-Hill, 1996.

SAUL TG, DUCKER TB: Effect of intracranial pressure monitoring and aggressive treatment on mortality in severe head injury. J Neurosurg 56:498-503, 1982.

SCHMIDTB, KLINGELHÖFER J, SCHWARZE JJ, SANDER $D$, WITTICH I: Noninvasive prediction of intracranial pressure curves using transcranial doppler ultrasonography and blood pressure curves. Stroke 28:2465-72, 1997.

\section{Endereço para correspondência:}

Almir Ferreira de Andrade

Av. Dr. Enéas de Carvalho Aguiar, 255 - Cerqueira César

$5^{\circ}$ andar - Secretaria de Neurocirurgia

CEP 05403-000 - São Paulo - SP 